Revue des patrimoines

\title{
Les enjeux d'une approche chronologique de la maison paysanne dans les Pays de la Loire
}

\section{François Le Bœuf}

\section{(2) OpenEdition}

Journals

Édition électronique

URL : http://journals.openedition.org/insitu/3754

DOI : $10.4000 /$ insitu.3754

ISSN : 1630-7305

Éditeur

Ministère de la culture

Référence électronique

François Le Bœuf, « Les enjeux d'une approche chronologique de la maison paysanne dans les Pays de la Loire », In Situ [En ligne], 9 | 2008, mis en ligne le 18 avril 2012, consulté le 01 mai 2019. URL : http://journals.openedition.org/insitu/3754; DOI : 10.4000/insitu.3754

Ce document a été généré automatiquement le 1 mai 2019.

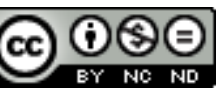

In Situ Revues des patrimoines est mis à disposition selon les termes de la licence Creative Commons Attribution - Pas d'Utilisation Commerciale - Pas de Modification 4.0 International. 
Les enjeux d'une approche chronologique de la maison paysanne dans les Pays de la Loire

\author{
François Le Bœuf
}

Cette approche chronologique de la demeure rurale est limitée à la seule maison paysanne, à l'exclusion de toute forme d'habitat rural élitaire, château, maison forte, manoir, maison dite "de maître " même si, nous le verrons, ces dernières ont un rôle certain à jouer dans l'évolution de cette maison paysanne ${ }^{1}$. 


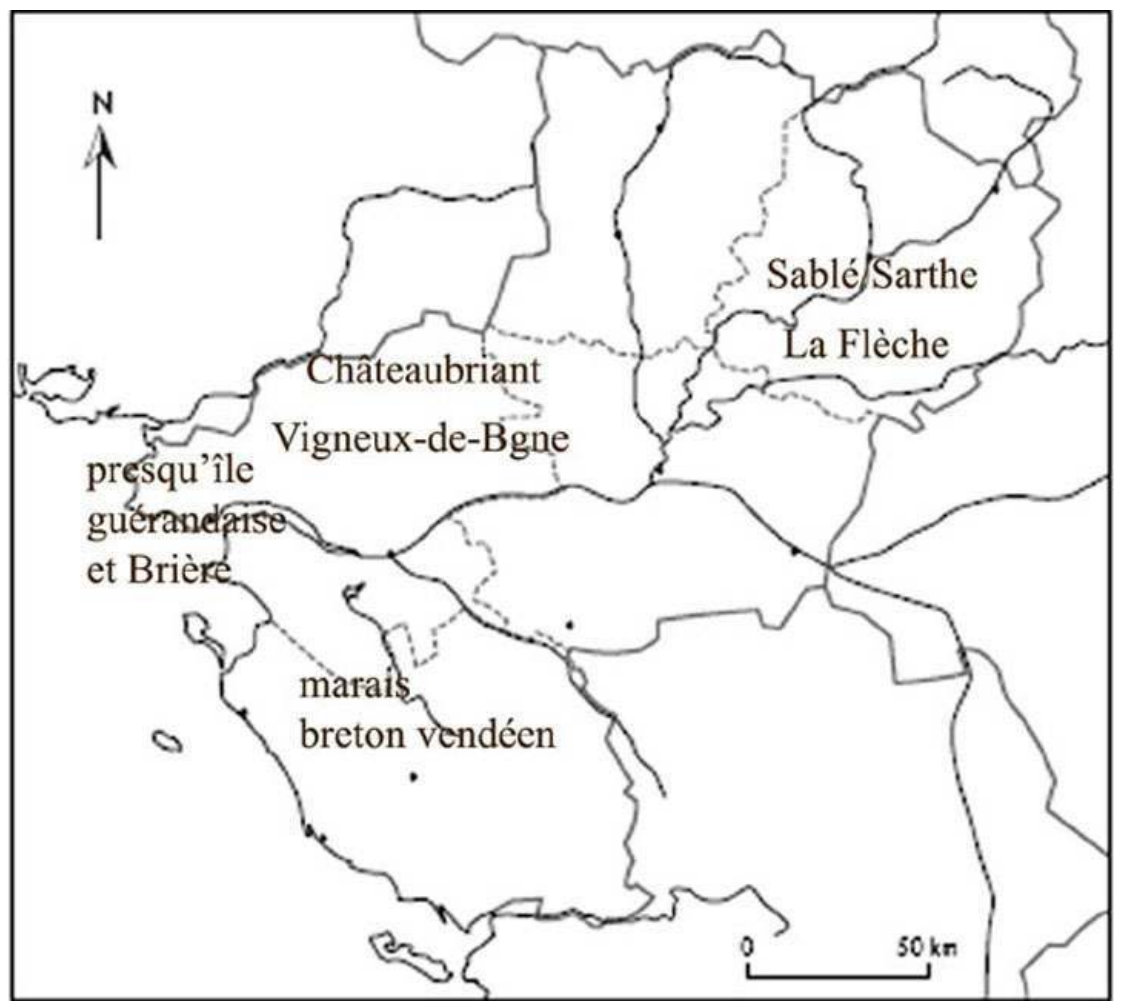

Carte de la région des Pays de la Loire, secteurs étudiés

(c) Inventaire général, région des Pays de la Loire

Elle est également limitée à un espace qui correspond à plusieurs secteurs des Pays de la Loire (fig. $\mathbf{n}^{\circ} \mathbf{1}$ ), le sud du Maine, à partir des cantons de Sablé-sur-Sarthe et de La Flèche, l'Anjou, sur la base d'exemples étudiés par les chercheurs du service départemental d'inventaire du Maine-et-Loire, les marais du nord de la Vendée, dans la région de SaintJean-de-Monts et enfin la Loire-Atlantique, où l'on distinguera surtout deux régions, le nord du département, autour de Châteaubriant et l'ouest, la presqu'île guérandaise. Dans ces deux régions, à des titres divers, l'architecture rurale présente de nombreux caractères communs avec le bâti rural breton: pour la première avec une assez large partie du sud de l'Ille-et-Vilaine, pour la seconde avec la frange littorale du Finistère sud et du Morbihan. Mentionnons pour mémoire la région de Notre-Dame-des-Landes, objet d'un travail très sommaire dans le cadre d'une étude d'impact du futur aéroport de Nantes-Atlantique.

3 L'étude chronologique de la maison paysanne se heurte à toutes sortes de difficultés, imputables à l'absence de critères de datation clairement identifiables. Produit architectural qui échapperait au domaine de l'art, ce bâti a d'abord suscité l'intérêt des géographes qui en ont proposé une approche essentiellement technique, par ailleurs parfaitement légitime. Ne parvenant pas à identifier d'éléments signifiants, les historiens de l'architecture se sont montrés souvent intimidés par cette question. Effet d'une " architecture sans architecte", d'une "architecture vernaculaire», dénuée de tout élément décoratif ${ }^{2}$, la maison paysanne a trop souvent été réduite à une simple suite de réponses pratiques à des problèmes concrets. 
Pour tenter de clarifier cette question de la chronologie, je proposerai de considérer une sorte de jalon fondé sur un constat a priori, celui de la généralisation de l'usage de la maçonnerie dans la construction paysanne, en s'attachant à chercher à situer cette mutation dans le temps. Plusieurs indices confortent cette idée d'une substitution de la pierre à d'autres matériaux - terre, bois, jonc, gazon, paille voire goémon dans la région du Croisic ${ }^{3}$. Cette mutation a été soulignée par plusieurs auteurs, notamment J.-M. Pérouse de Montclos ${ }^{4}$ et André Mussat, pour la Bretagne. Elle a été également largement confirmée par les archéologues ${ }^{5}$.

Figure 2

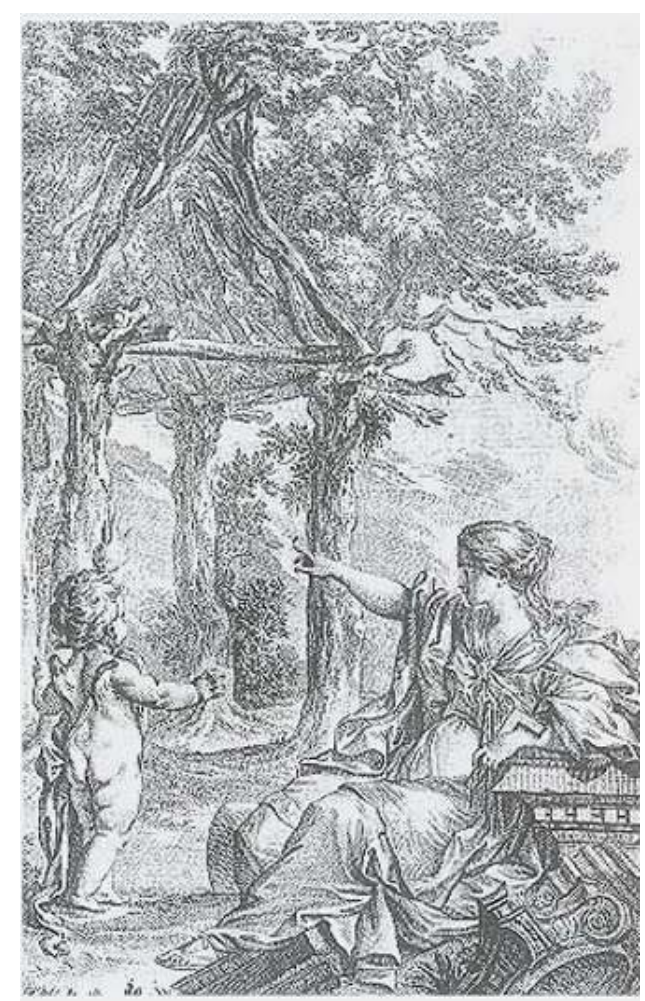

La hutte primitive de Jean-Baptiste Laugier, tirée de « Essai sur l'architecture », 1755

(c) Inventaire général, région des Pays de la Loire

Poser la question en ces termes revient à évoquer le thème plus ou moins utopique de la "hutte primitive", qui a retenu l'attention de plus d'un architecte, de Vitruve à Le Corbusier, en passant par Philibert de l'Orme ou Jean-Baptiste Laugier (fig. $\mathbf{n}^{\circ} \mathbf{2}$ ). Ici, je ne peux que renvoyer le lecteur à la passionnante étude de l'historien anglais Joseph Rykwert $^{6}$, qui constate que la célébration de cette forme primitive d'habitat, effective dans la plupart des civilisations de la planète, constituerait une garantie de la continuité temporelle.

Dans le territoire qui nous concerne, les témoins de cette "hutte" sont encore perceptibles, de diverses manières. A travers la toponymie : la Hutte, commune de Rougé, dans le nord de la Loire-Atlantique, ou, de manière plus ironique, la Maison de Paille, incluse par hasard dans le domaine de Grand-Jouan, à Nozay (Loire-Atlantique), établissement d'enseignement agricole d'avant-garde au milieu du XIX siècle. D'autres indices apparaissent également au détour de quelque pièce d'archives : en 1720, l'état des lieux d'un jardin proche de Châteaubriant, loué à un prêtre, mentionne, délaissées dans 
un recoin du terrain et désormais inutiles, deux loges couvertes et closes de panaches et de joncs, la cheminée de massonnail .

7 Ces mentions de ce qu'il faut bien considérer comme des vestiges de la " hutte primitive » ne sont pas sans évoquer les résultats des recherches archéologiques, menées en Bretagne notamment ${ }^{8}$, qui ont mis en évidence l'existence d'un bâti paysan construit en matériaux fragiles et éphémères. On en relève, ici et là, quelques survivances, qui ne cessent d'étonner. Ainsi le village de bûcherons de Talforest, à Plumelin dans le Morbihan, repéré dans les années 1940 dans le cadre de l'enquête sur l'architecture paysanne de France'. Son étude a montré que ce bâti, aujourd'hui détruit, a tout naturellement renoué avec des traditions ancestrales. J'ai eu l'occasion de faire le même constat à propos de la bourrine des marais du nord de la Vendée, rustique construction en bauge datant tout au plus du $\mathrm{XIX}^{\mathrm{e}}$ siècle et du début du XX $\mathrm{XX}^{\mathrm{e}}$, dont le souvenir semblait avoir disparu depuis le XVII siècle, pour réapparaître à la faveur de circonstances très particulières. Notons également la survivance, malheureusement de moins en moins vérifiée depuis quelques décennies, de petites resserres, souvent appelées loges, faites d'une ossature de bois recouverte de brande, que certains archéologues sont tentés de voir dériver de pratiques constructives datant du néolithique ${ }^{10}$ (loge couverte de brandes à Chartrené, dans le nord du Maine-etLoire) (fig. $\mathbf{n}^{\circ}$ 3).

Figure 3

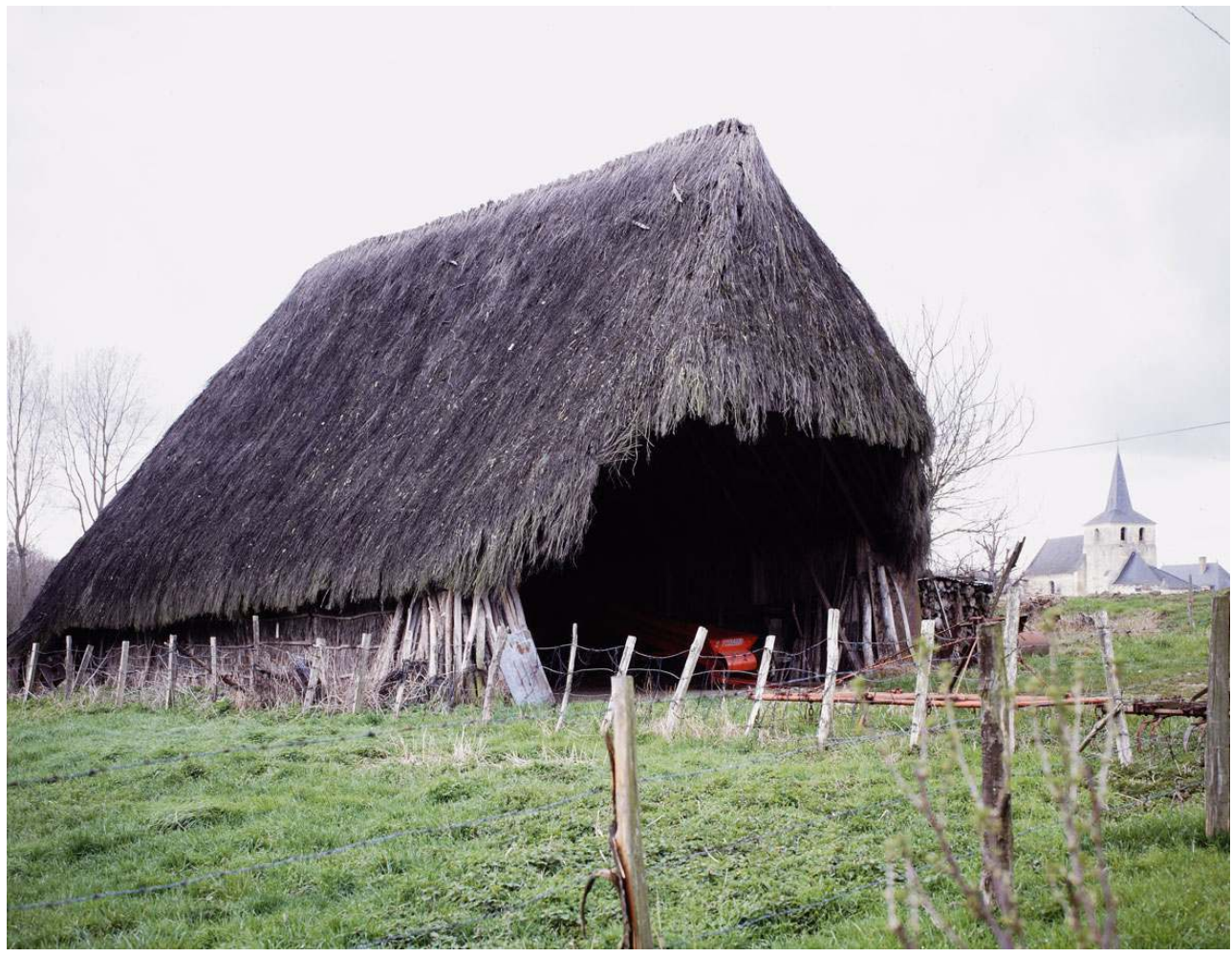

Chartrené (Maine-et-Loire), la Baudinière. Loge couverte de brandes

(c) Inventaire général, région des Pays de la Loire

8 Tous ces éléments, bien que du plus grand intérêt, ne permettent guère de répondre à la question initialement posée: dans quel cadre chronologique peut-on situer cette « révolution » de la maçonnerie ? Notons tout d'abord qu'elle ne s'est pas produite de la même manière dans l'ensemble de la région que nous considérons. Dans certains secteurs, 
les territoires s'étendant au sud de Nantes par exemple, il n'est même pas certain que la question soit pertinente, tant les bâtiments ruraux les plus anciens - construits en pierre ! - frappent par le caractère rustique de leur mise en œuvre. Le logis paysan de la Cartière, à Thouaré-sur-Loire dans la banlieue nantaise (fig. $\mathbf{n}^{\circ} \mathbf{4}$ ), dont ne subsiste que la face antérieure, avait pour ouverture une porte couverte par un arc bloqué au mortier et n'était éclairé que par un jour aux proportions très réduites. Non loin, une autre maison de facture très similaire n'est percée que de la seule porte, à l'exclusion de toute fenêtre ou jour. Pays où domine la "maison latine ", selon les termes de l'ethnologue nantais Joseph-Stany Gauthier dans les années $1930^{11}$, cette région du sud de la Loire contraste très fortement par son bâti avec les autres secteurs de la région, où domine au contraire la « maison gauloise », appellations dont nous laisserons la responsabilité à l'auteur.

Figure 4

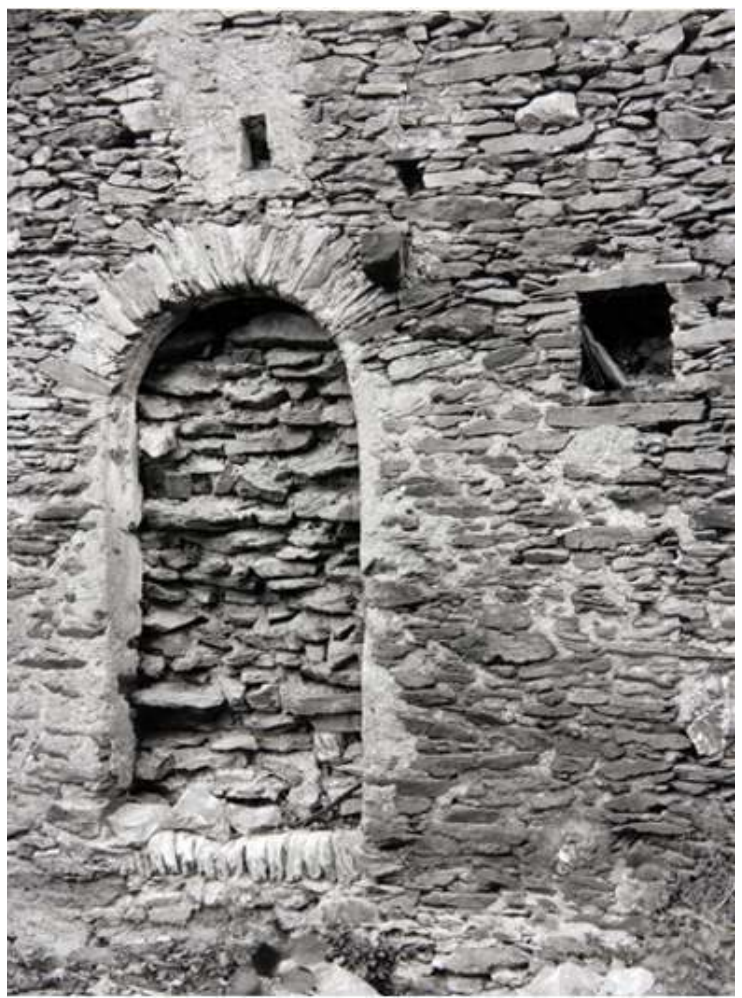

Thouaré-sur-Loire (Loire-Atlantique), la Cartière. Logis paysan, vestige (c) Inventaire général, région des Pays de la Loire

9 Si la mutation vers la maçonnerie est effective partout ailleurs dans les Pays de la Loire, il semble bien qu'elle ne se soit pas manifestée partout au même moment. Par exemple, un certain nombre d'indices semblent indiquer qu'elle serait advenue relativement tôt dans le Maine, dès l'époque médiévale. En revanche, dans la partie bretonne de la région, il conviendrait de reculer cette période d'environ deux siècles.

Sur la foi de quelles observations pouvons-nous avancer de telles hypothèses? 


\section{Critères d'ordre stylistique}

\section{La cheminée}

11 Dans la maison paysanne, la cheminée apparaît comme l'élément le plus à même de présenter tel caractère stylistique - emprunté à l'habitat élitaire, à n'en pas douter, mais nous verrons que ce mimétisme constitue un détail clé de l'évolution stylistique de la maison paysanne - de nature à fournir des indications d'ordre chronologique. Le soin accordé à la mise en œuvre de la cheminée s'appréhende aisément à la lecture des remarquables réflexions de l'historien britannique G. Meirion-Jones sur le foyer en Bretagne $^{12}$ qui met en évidence l'importance de la fonction symbolique de la cheminée dans la maison. Notons d'ailleurs que ces réflexions peuvent tout autant s'appliquer aux régions limitrophes de cette province.

Figure 5

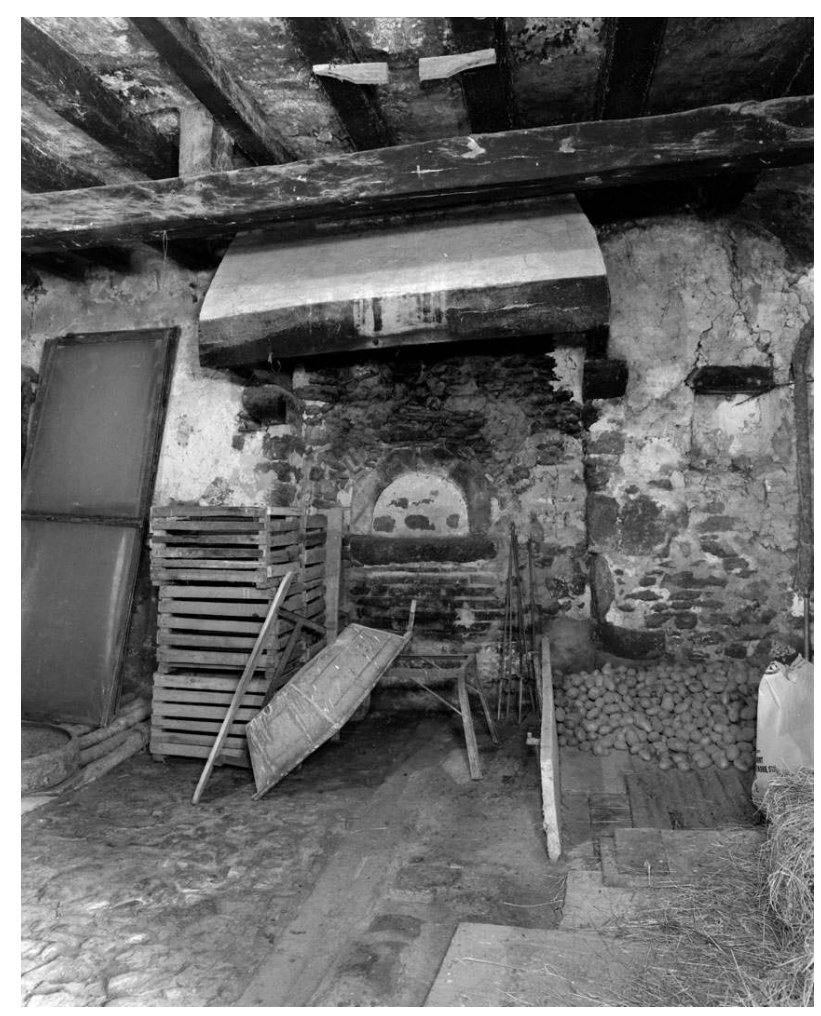

Auvers-le-Hamon (Sarthe), Vaillé. Cheminée

(c) Inventaire général, région des Pays de la Loire

12 Adossée à l'un des pignons de la maison, la cheminée est à faux manteau, son conduit est maçonné en moellon enduit (parfois en torchis dans la presqu'île guérandaise), porté par un linteau et des consoles indifféremment en pierre, parfois de taille, ou en bois. La mise en œuvre des consoles serait sans doute à même de fournir des indications chronologiques. Je serais ainsi tenté de faire remonter à une date assez reculée (fin de la période médiévale ?) une cheminée (fig. $\mathbf{n}^{\circ}$ 5) repérée dans une ferme à Auvers-le-Hamon (canton de Sablé-sur-Sarthe), dont les consoles consistent en de simples moellons à peine équarris. Cependant, une facture rustique n'est pas toujours gage d'ancienneté. 
D'autres supports de cheminée sont plus aisément assimilables, par comparaison avec une cheminée observée dans un manoir voisin, datant du XIII ${ }^{e}$ siècle, à des ouvrages datant de la période médiévale, au XIII ${ }^{\mathrm{e}}$ ou au XIV ${ }^{\mathrm{e}}$ siècle (Chantemêle à Auvers-le-Hamon) (fig. $\mathbf{n}$ - 6), sauf cas de remploi peu probable ici - on notera toutefois que linteau en bois et hotte sont très probablement postérieurs. Le même raisonnement pourrait être tenu à propos de la cheminée de l'Artenuère à Crosmières (région de La Flèche) (fig. $\mathbf{n}^{\circ} \mathbf{7}$ ), dont les corbeaux naïvement taillés pourraient dater $d u X V^{e}$ ou du début du XVI ${ }^{e}$ siècle.

\section{Figure 6}

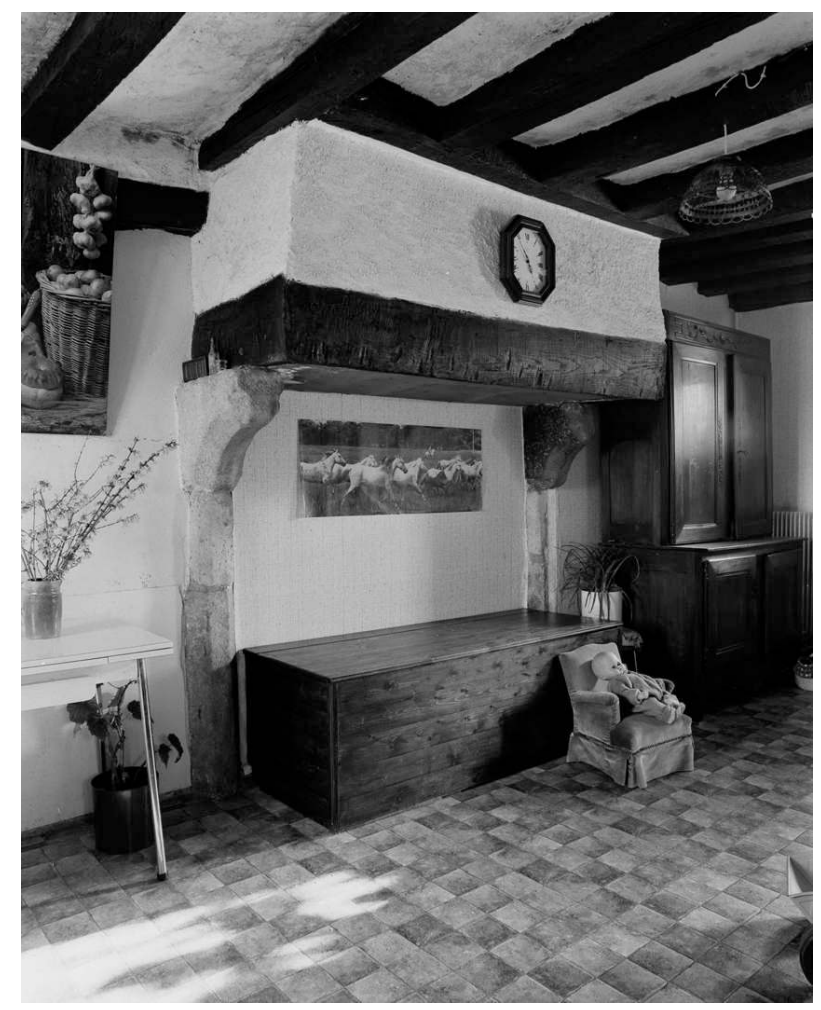

Auvers-le-Hamon (Sarthe), Chantemêle. Cheminée, XIIIe-XIVe siècles

(C) Inventaire général, région des Pays de la Loire 
Figure 7

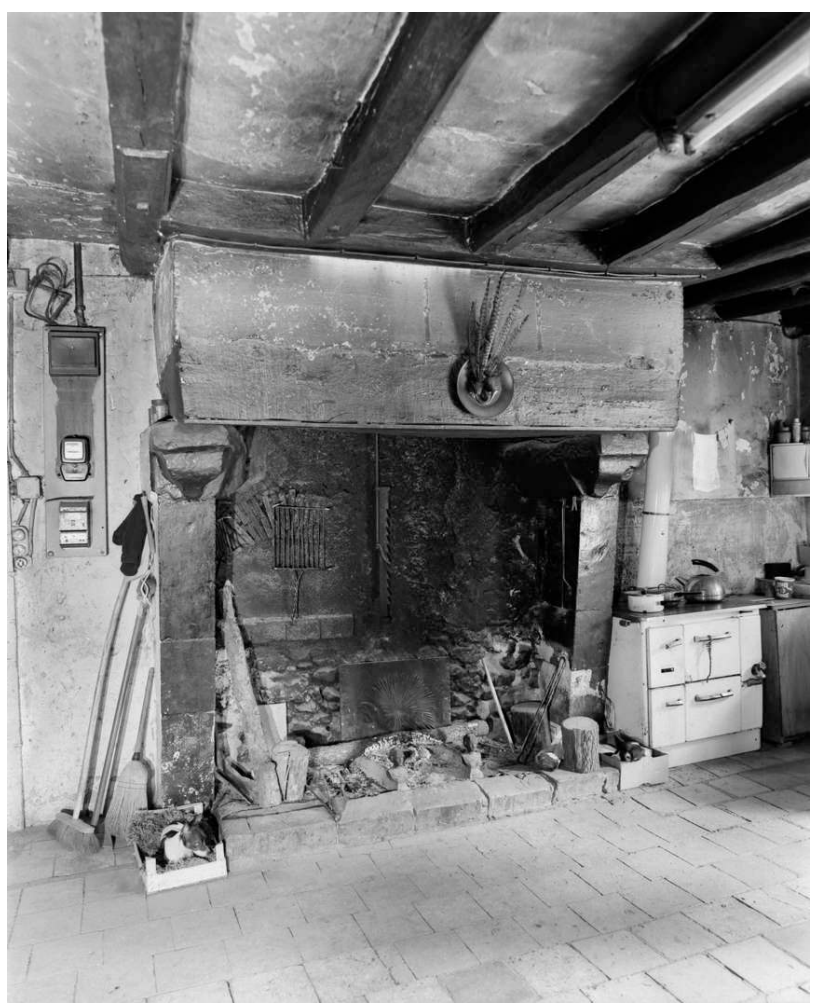

Crosmières (Sarthe), I'Arthenuère. Cheminée, $X V$ e-XV|e siècles (C) Inventaire général, région des Pays de la Loire 
Figure 8

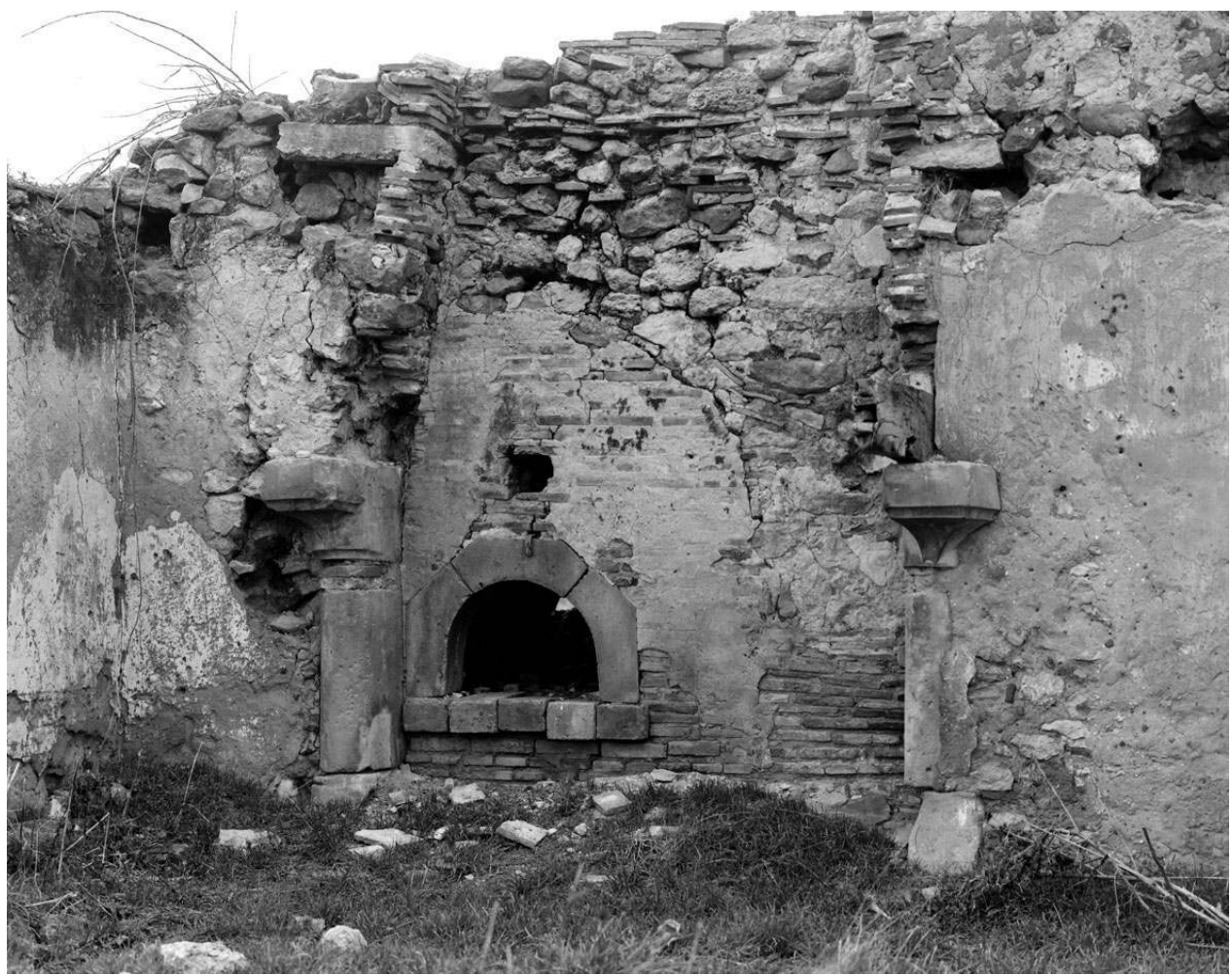

Crosmières (Sarthe), la Hauberdière. Cheminée, fin XVe siècle

(c) Inventaire général, région des Pays de la Loire

14 Cependant, ce type d'approche peut se révéler hasardeux : une très belle cheminée de la fin du XV $\mathrm{XV}^{\mathrm{e}}$ siècle, dans la ferme de la Hauberdière, également à Crosmières (fig. $\left.\mathbf{n}^{\circ} \mathbf{8}\right)$ correspond assurément à un remploi effectué au milieu du XIX ${ }^{\mathrm{e}}$ siècle à partir d'un manoir complètement dépecé à cette époque.

15 Une cheminée repérée à Guerreau à Auvers-le-Hamon (fig. $\mathbf{n}^{\circ}$ 9) semble d'une structure assez voisine de celle de Chantemêle, située d'ailleurs dans la même commune. Mais l'information n'ouvre guère de perspectives : le bâtiment se trouve aujourd'hui noyé dans une construction dont le plan prend le parfait contre-pied de son parti primitif, n'ouvrant la porte qu'à de bien pauvres conjectures (fig. $\left.\mathbf{n}^{\circ} \mathbf{1 0}\right)$. 
Figure 9

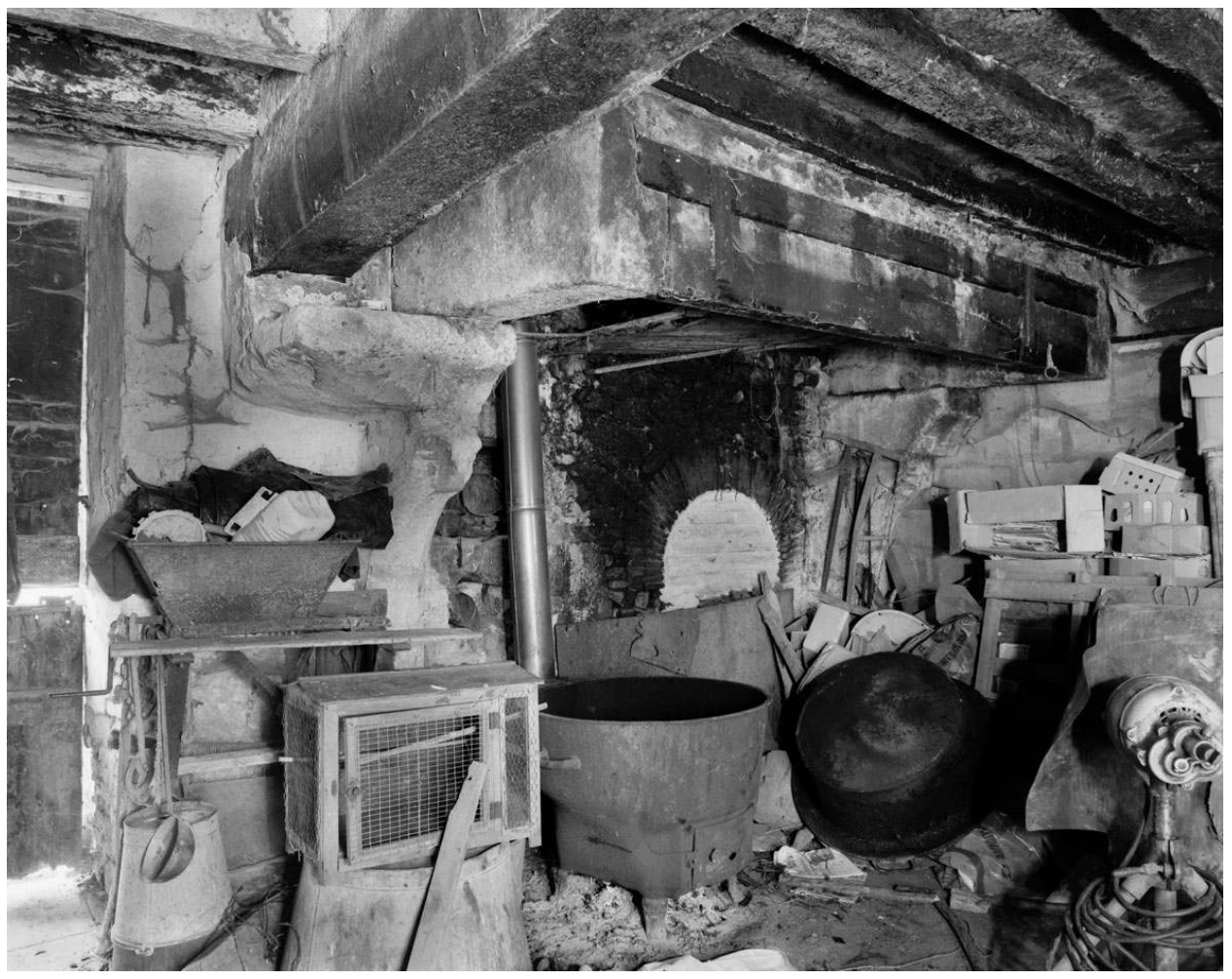

Asnières-sur-Vègre (Sarthe), Guerreau. Cheminée, XIIIe-XIVe siècles ?

(c) Inventaire général, région des Pays de la Loire 
Figure 10

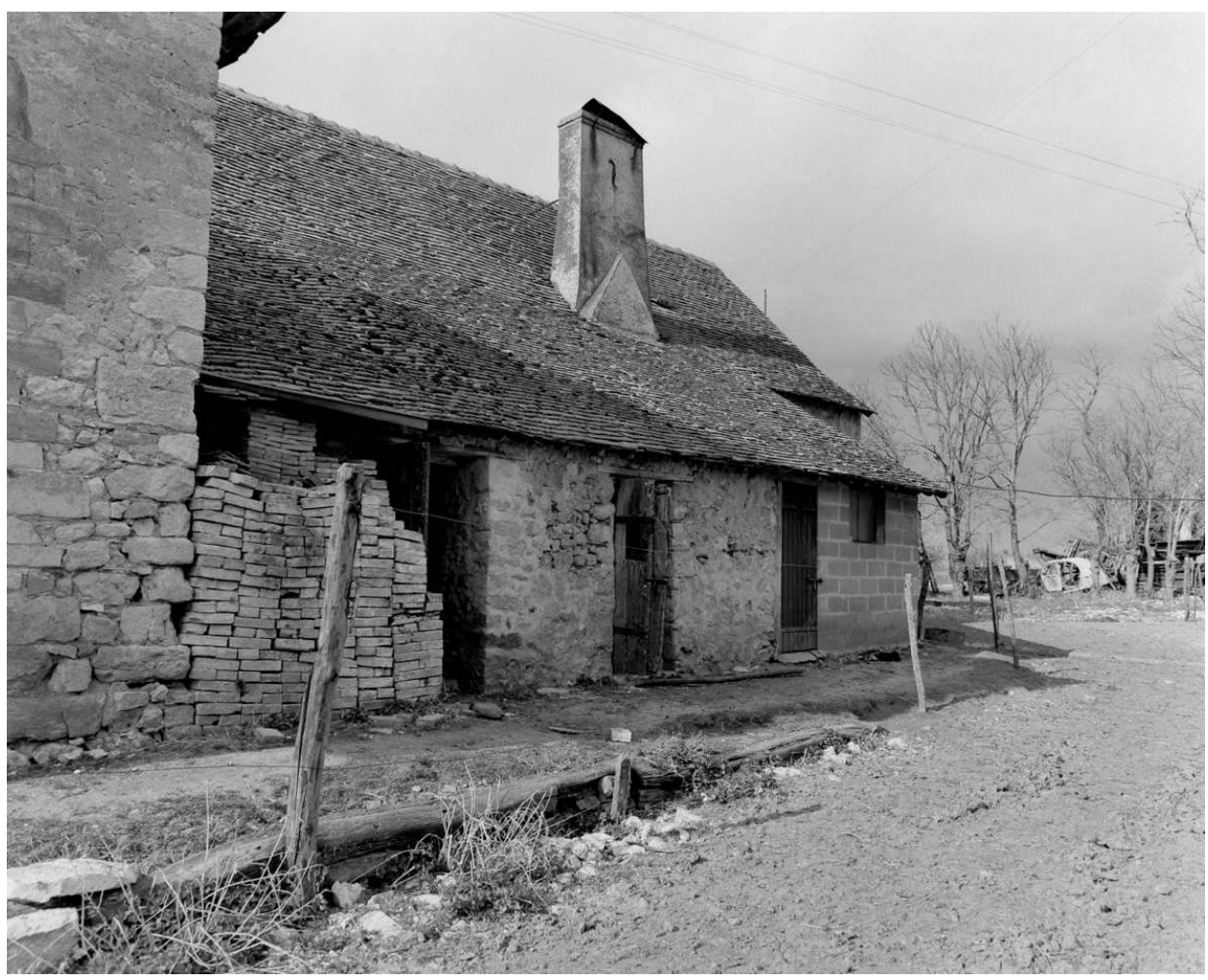

Asnières-sur-Vègre (Sarthe), Guerreau. Maison

(c) Inventaire général, région des Pays de la Loire 
Figure 11

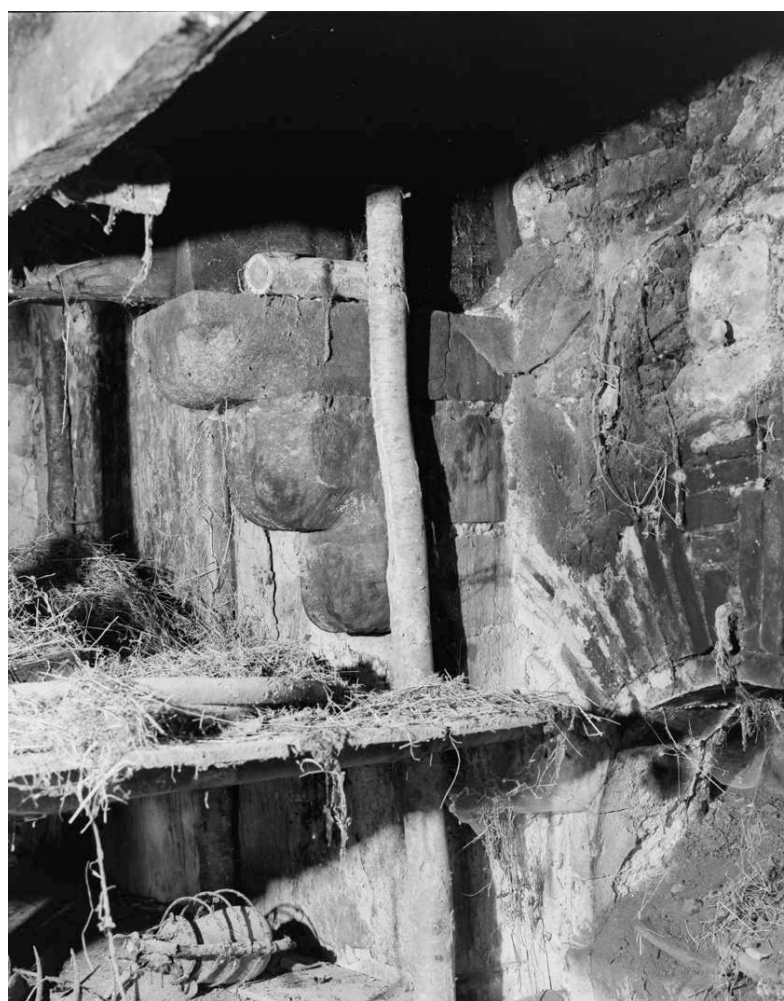

Bazouges-sur-le-Loir (Sarthe), les Guérets. Corbeau de cheminée à triple quart-de-rond, XIVe-XVe siècles

(c) Inventaire général, région des Pays de la Loire

16 Heureusement, certains vestiges paraissent plus dignes de foi, ainsi ce corbeau de cheminée à triple quart-de-rond dans un logis paysan (fig. $\mathbf{n}^{\circ}$ 11) (les Guérets à Bazougessur-le-Loir, près de La Flèche) entièrement remanié par ailleurs à l'époque moderne et au $\mathrm{XIX}^{\mathrm{e}}$ siècle, est d'un type très courant dans les manoirs de la fin du Moyen Âge dans cette région. 
Figure 12

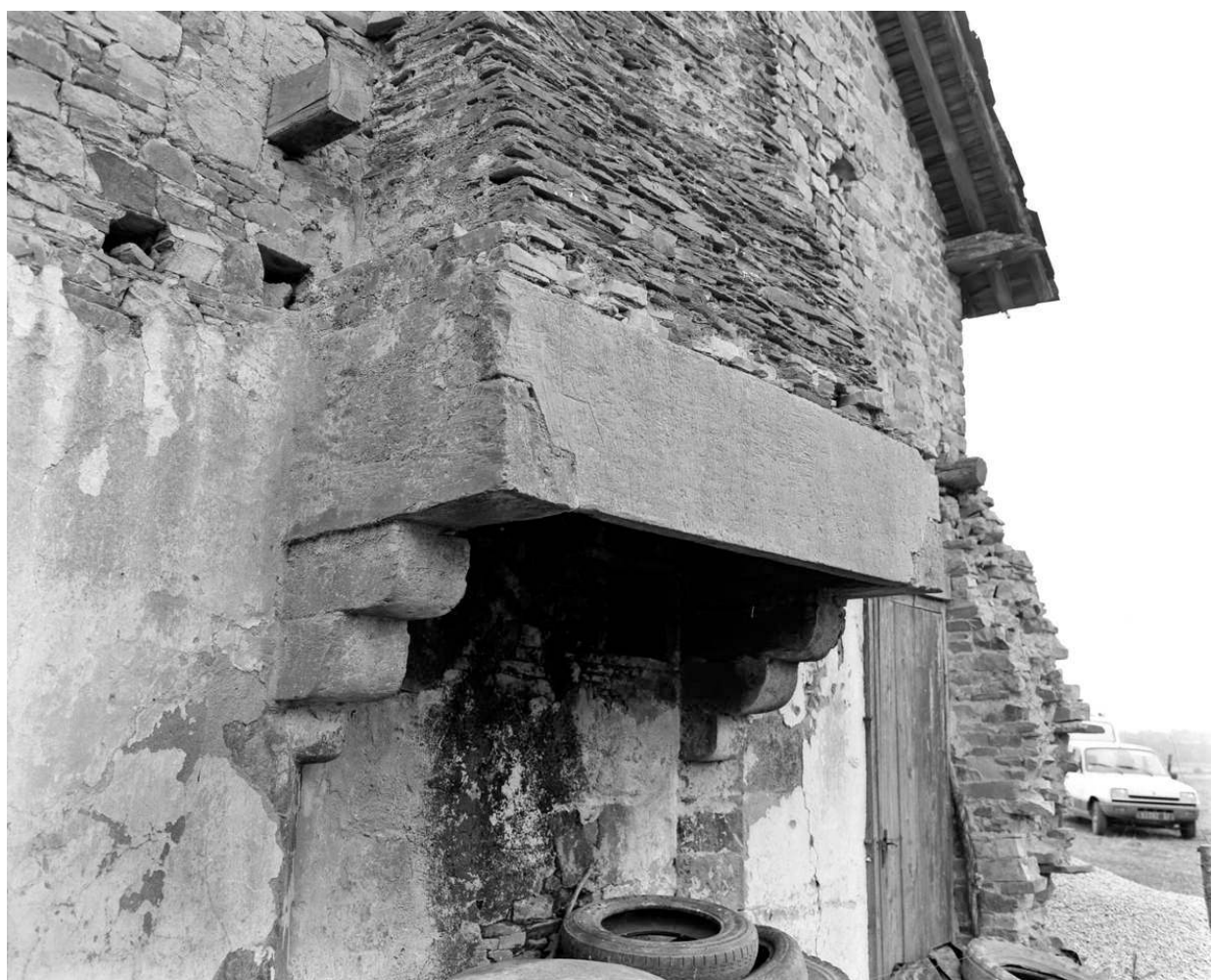

Villepôt (Loire-Atlantique), I'Hionnière. Cheminée, XVIIe siècle

(c) Inventaire général, région des Pays de la Loire

17 Mais il faut se prémunir des recettes trop simples : vérité dans un canton, erreur dans l'autre! Dans le nord de la Loire-Atlantique, ce type de corbeau est d'un usage très courant sur des logis datant en général du XVII siècle (l'Hionnière à Villepôt) (fig. $\mathbf{n}^{\circ}{ }^{12}$ ). L'observation attentive évite de tomber dans l'erreur: patine différente de la pierre, roussard dans la Sarthe, schiste dans la Loire-Atlantique, taillé d'une manière plus «moderne».

\section{La façade}




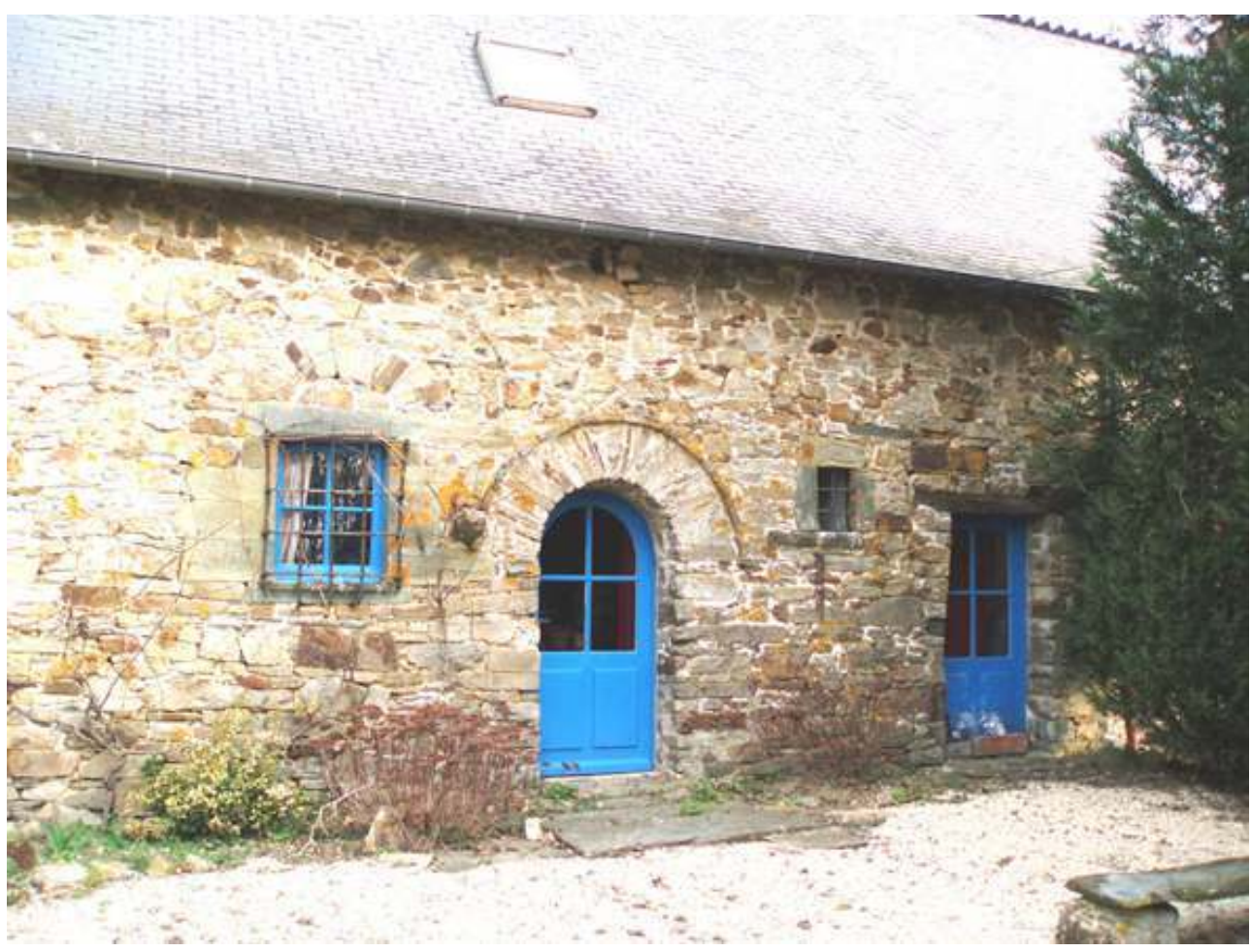

Villepôt (Loire-Atlantique), La Génauderie. Logis paysan, XVIIe siècle

(c) Inventaire général, région des Pays de la Loire

Le nord de la Loire-Atlantique, autour de Châteaubriant, de même qu'une large frange méridionale du département de l'Ille-et-Vilaine, est caractérisé par un corpus relativement important de logis paysans dont la façade fait l'objet d'une exécution particulièrement soignée (la Génauderie à Villepôt) (fig. $\mathbf{n}^{\circ}$ 13). La porte couverte par un arc en plein-cintre bloqué au mortier, souvent souligné par un naif cordon d'archivolte fait de petites dalles grossièrement taillées, est associée à une fenêtre dont l'encadrement

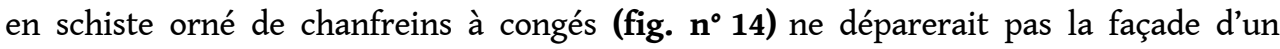
manoir de la seconde moitié du XVe siècle, à cette différence près que le millésime gravé au centre du linteau indique ici la date de 1606 . Dans ce cas présent, la fidélité au modèle de la maison noble ne fait guère de doute puisque, à l'intérieur, la fenêtre va jusqu'à en imiter les coussièges (fig. $\mathbf{n}^{\circ} \mathbf{1 5}$ ), inconfortablement logés dans l'étroite embrasure. 


\section{Figure 14}

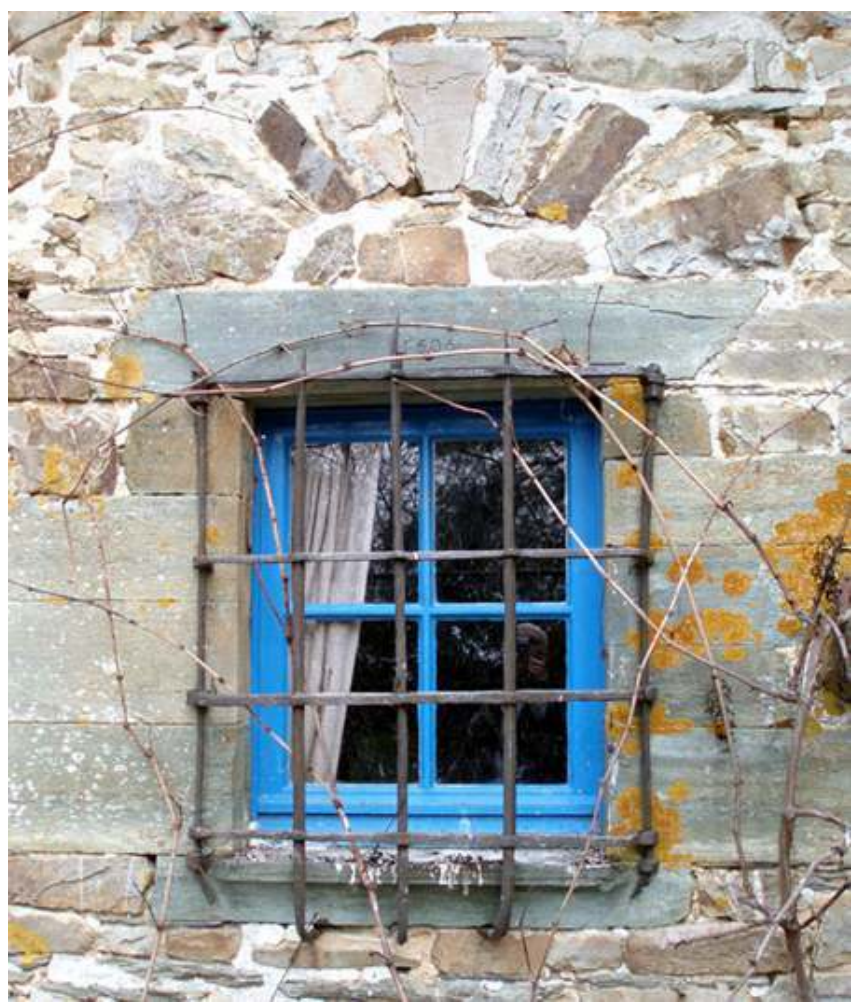

Villepôt (Loire-Atlantique), La Génauderie. Fenêtre dont le linteau porte la date de 1606 (c) Inventaire général, région des Pays de la Loire 
Figure 15

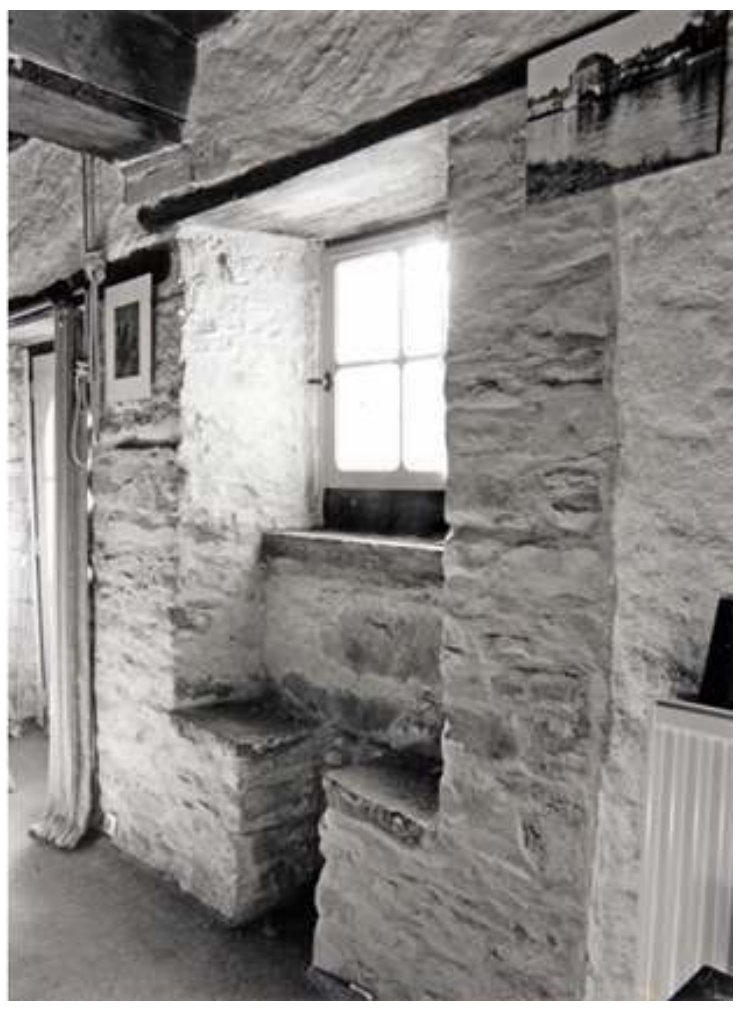

Villepôt (Loire-Atlantique), La Génauderie. Coussièges

(c) Inventaire général, région des Pays de la Loire

\section{Figure 16}

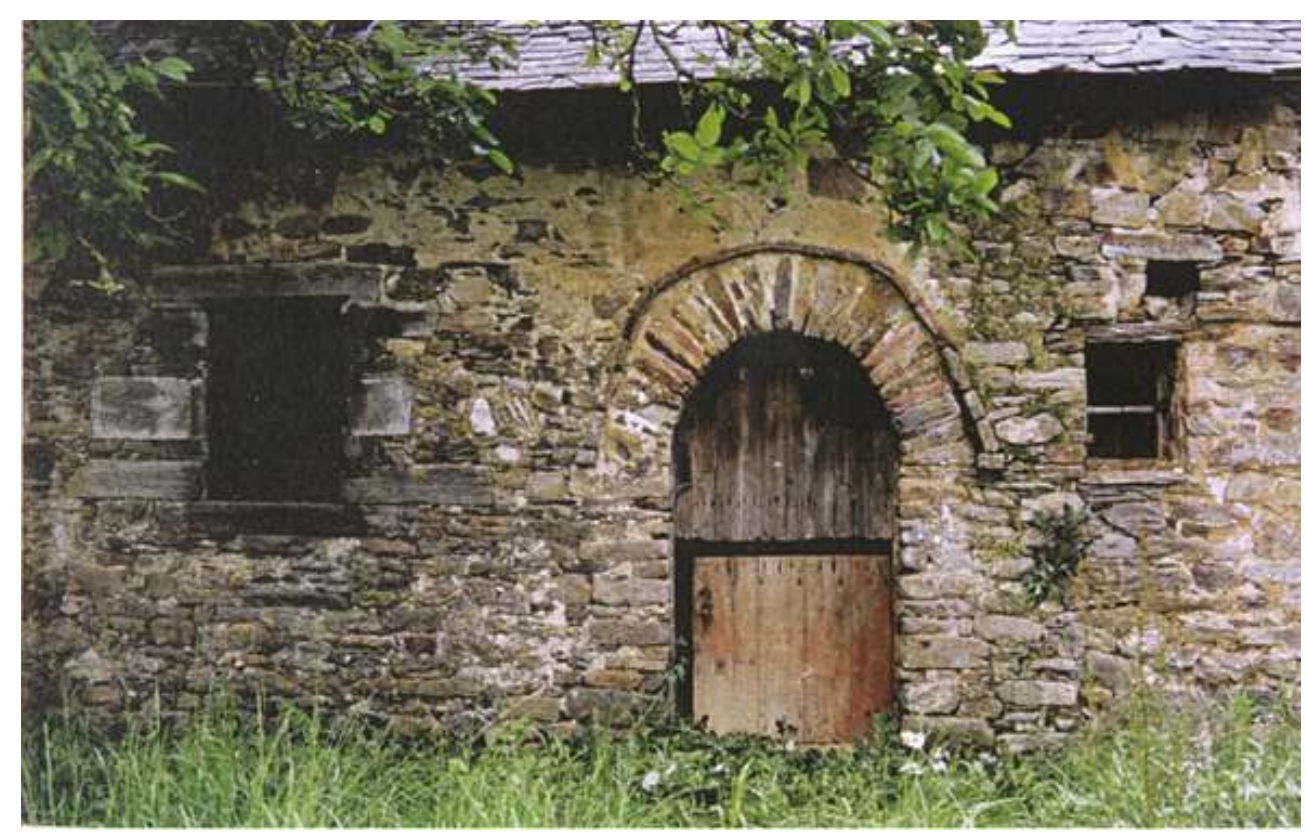

Noyal-sur-Brütz (Loire-Atlantique), le Mortier. Logis paysan, XVIIe siècle

(C) Inventaire général, région des Pays de la Loire 
Ce corpus frappe par sa grande cohérence (fig. $\mathbf{n}^{\circ}$ 16) le Mortier à Noyal-sur-Brütz, (fig. $\mathbf{n}$ -17) le Bas-Plessis à Villepôt, (fig. $\mathbf{n}^{\circ}$ 18) les Nardais à Châteaubriant), comme si un modèle unique de façade s'était brusquement répandu comme une traînée de poudre.

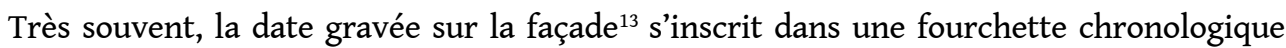
qui se situe à peu près entre 1630 et 1690 . De plus, à côté du millésime, apparaitt fréquemment le patronyme du maître de céans, parfois accompagné de celui de son épouse. Ces inscriptions, ainsi que le soin apporté à l'exécution de la façade, sembleraient révéler l'émergence d'une petite élite rurale, d'autant mieux valorisée que ces nouvelles demeures tranchaient assurément par leur " modernité $^{14}$ » sur l'habitat paysan ordinaire. Les modèles sont fournis par l'habitat noble de la région, dont on s'attache à retenir les éléments les plus ostentatoires (fenêtre du manoir, caractère solennel de l'entrée soulignés par l'arc en plein-cintre...). Les avatars de cette sorte de mimétisme constructif, que l'on constate dans toutes les strates de la société, ont été notamment soulignées par Jean-Marie Pérouse de Montclos.

Figure 17

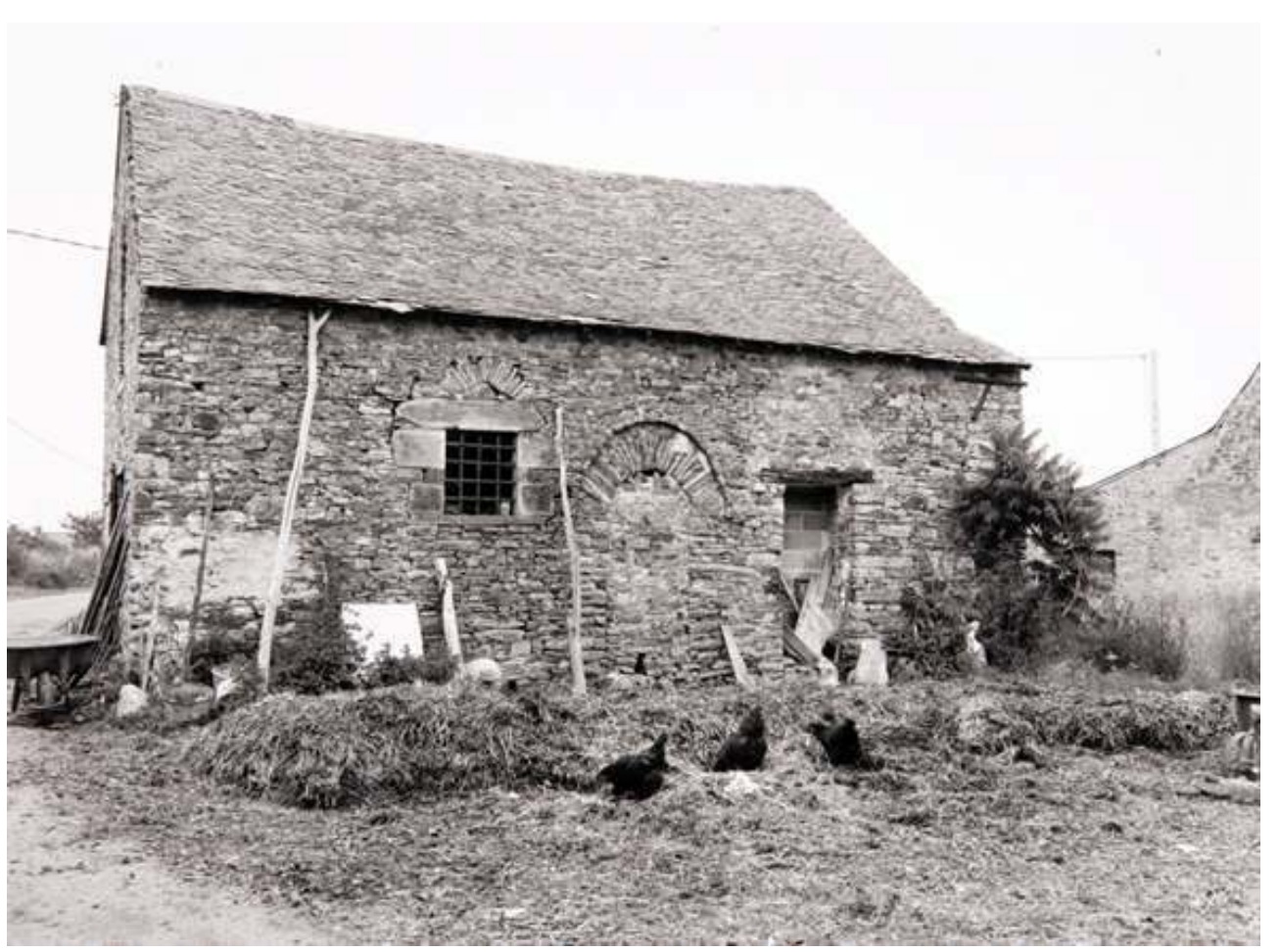

Villepôt (Loire-Atlantique), le Bas-Plessis. Logis paysan, XVIIe siècle

(c) Inventaire général, région des Pays de la Loire 
Figure 18

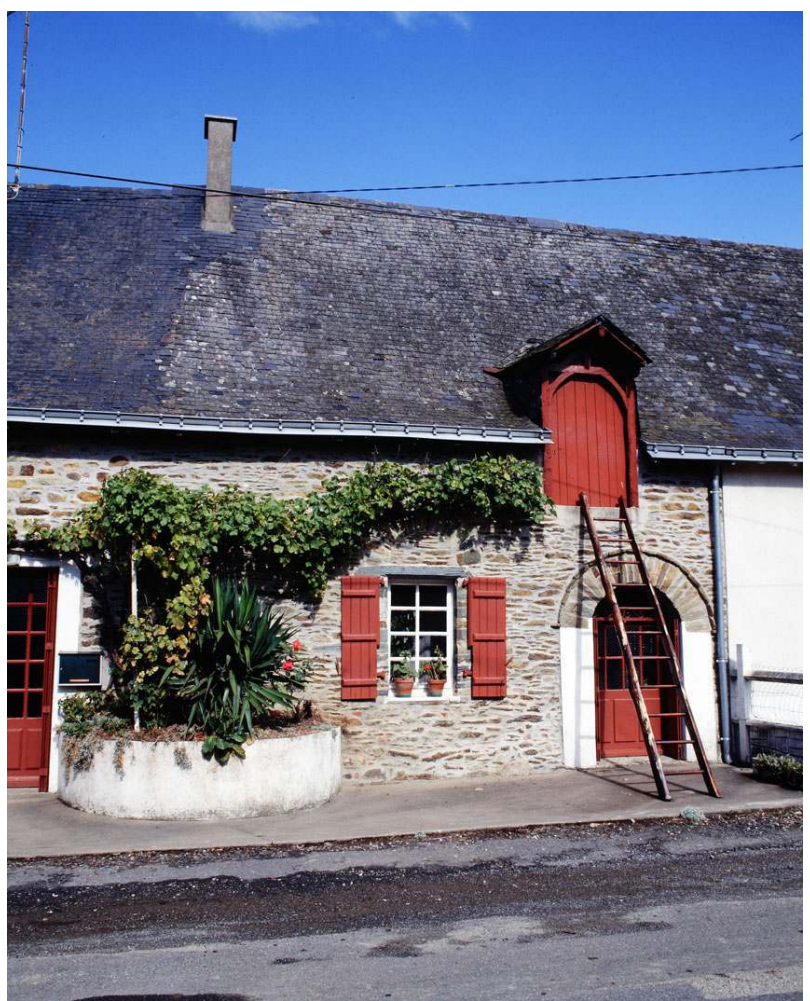

Châteaubriant (Loire-Atlantique), les Nardais. Logis paysan, XVIIe siècle (C) Inventaire général, région des Pays de la Loire

Passé cette période, le bâti paysan en maçonnerie tend à se banaliser, sous l'effet du nombre probablement, ce qui aurait tendance à conforter l'hypothèse d'une phase pionnière de la révolution de la pierre au XVII ${ }^{\mathrm{e}}$ siècle. À la Glivère, Villepôt (fig. $\mathbf{n}^{\circ}$ 19), le logis date du XVIII ${ }^{e}$ siècle, et a été probablement retouché au siècle suivant: on n'y retrouve pas la même volonté de donner une harmonie à la façade. Quelques timides éléments de décor apparaissent parfois, tels les linteaux délardés sur la partie gauche (XVIII ${ }^{e}$ siècle ou tout début du XIX ${ }^{e}$ ) du logis de la Cointerie, à Villepôt (fig. $\mathbf{n}^{\circ}$ 20), une des premières manifestations de l'irruption de motifs décoratifs d'origine urbaine dans le bâti paysan. 
Figure 19

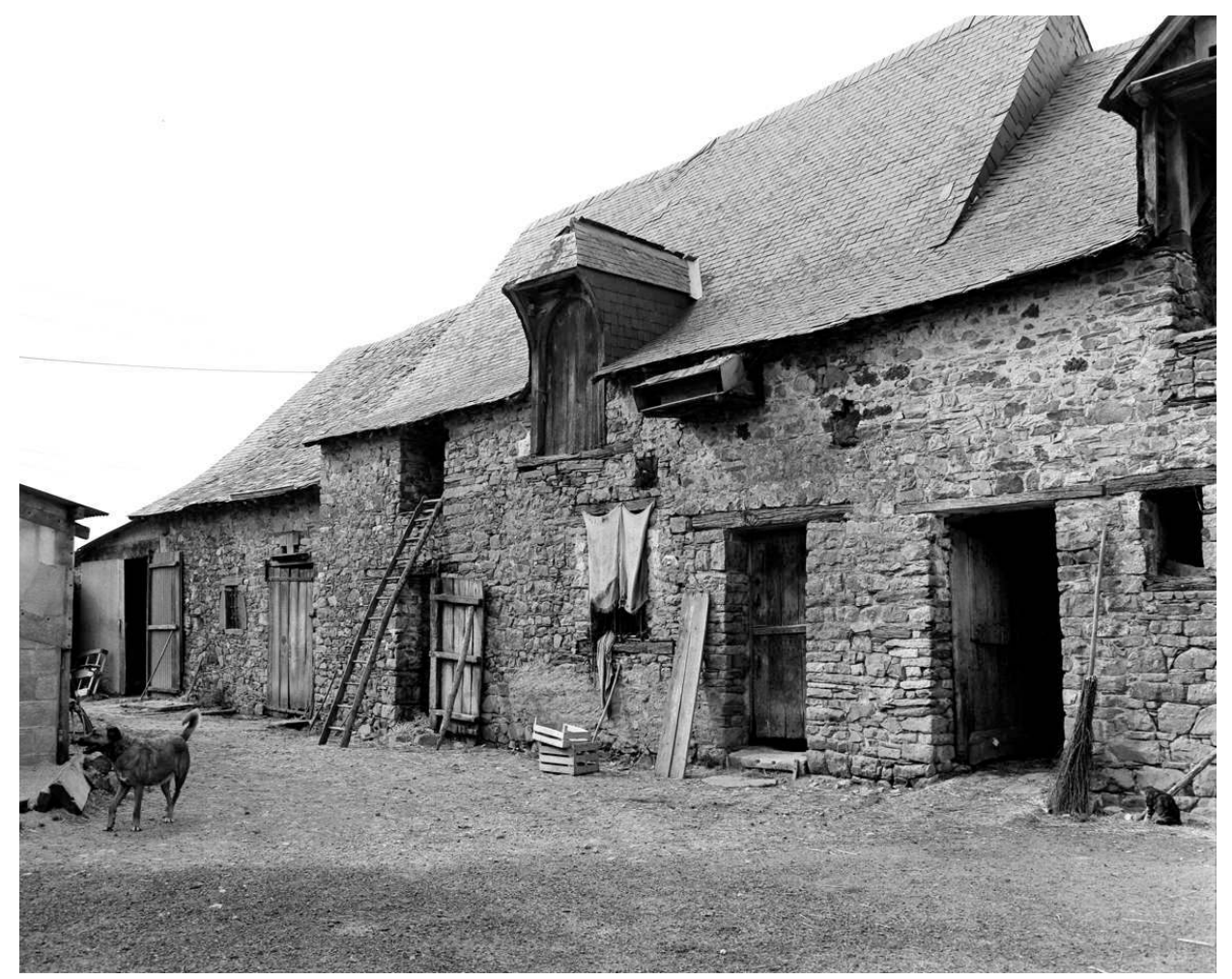

Villepôt (Loire-Atlantique), la Glivière. Logis paysan, XVIIIe siècle

(c) Inventaire général, région des Pays de la Loire 


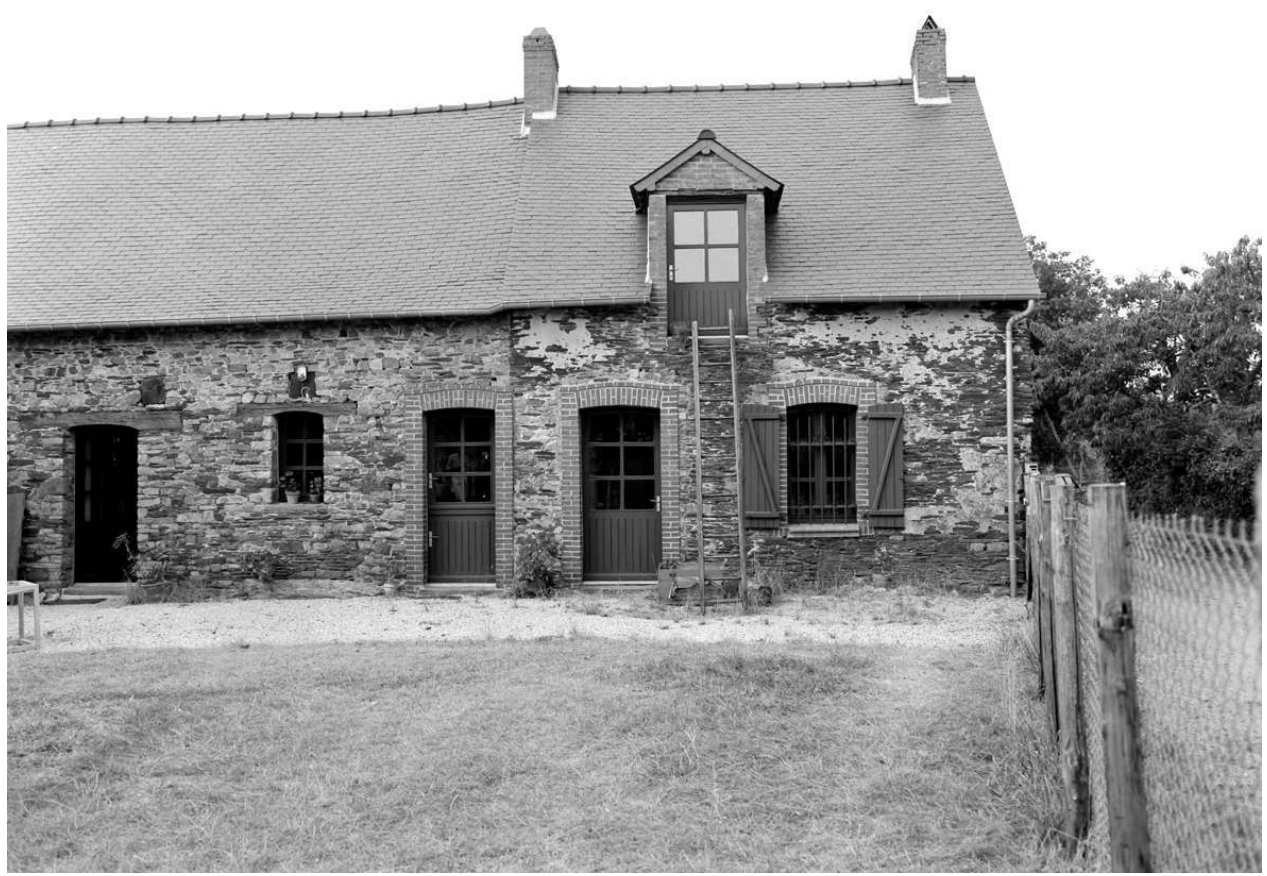

Villepôt (Loire-Atlantique), la Cointerie. Logis paysan, fin XVIIII-XIXe siècles

(c) Inventaire général, région des Pays de la Loire

Cette particularité du logis paysan est-elle imputable au caractère relativement tardif de son apparition? Dans le Maine, où la « révolution » de la maçonnerie s'est certainement manifestée plus tôt (quelques échantillons dateraient de la fin de la période médiévale, mais le gros du corpus s'est assurément constitué dans le courant du XVI ${ }^{e}$ siècle), la mise en œuvre des logis est plus banale : le caractère plus diffus de son extension dans le temps et dans l'espace pourrait l'expliquer. Peut-être le pays de Châteaubriant a-t-il bénéficié des conséquences d'une évolution tardive, à une époque où le travail sur la forme revêtait une importance accrue?

On retrouve quelques équivalents, certes moins affirmés, ailleurs en Loire-Atlantique. Le logis du Château, à Vigneux-de-Bretagne (fig. n $^{\circ 1}$ ), dont le millésime 1679 est gravé sur la façade, présente une porte couverte en anse de panier, affirmant une fois de plus l'importance du manoir médiéval comme modèle. La même remarque vaut pour cette porte de logis briéron (fig. $\mathbf{n}^{\circ} \mathbf{2 2}$ ), couverte par un arc en plein-cintre en pierre de taille. 
Figure 21

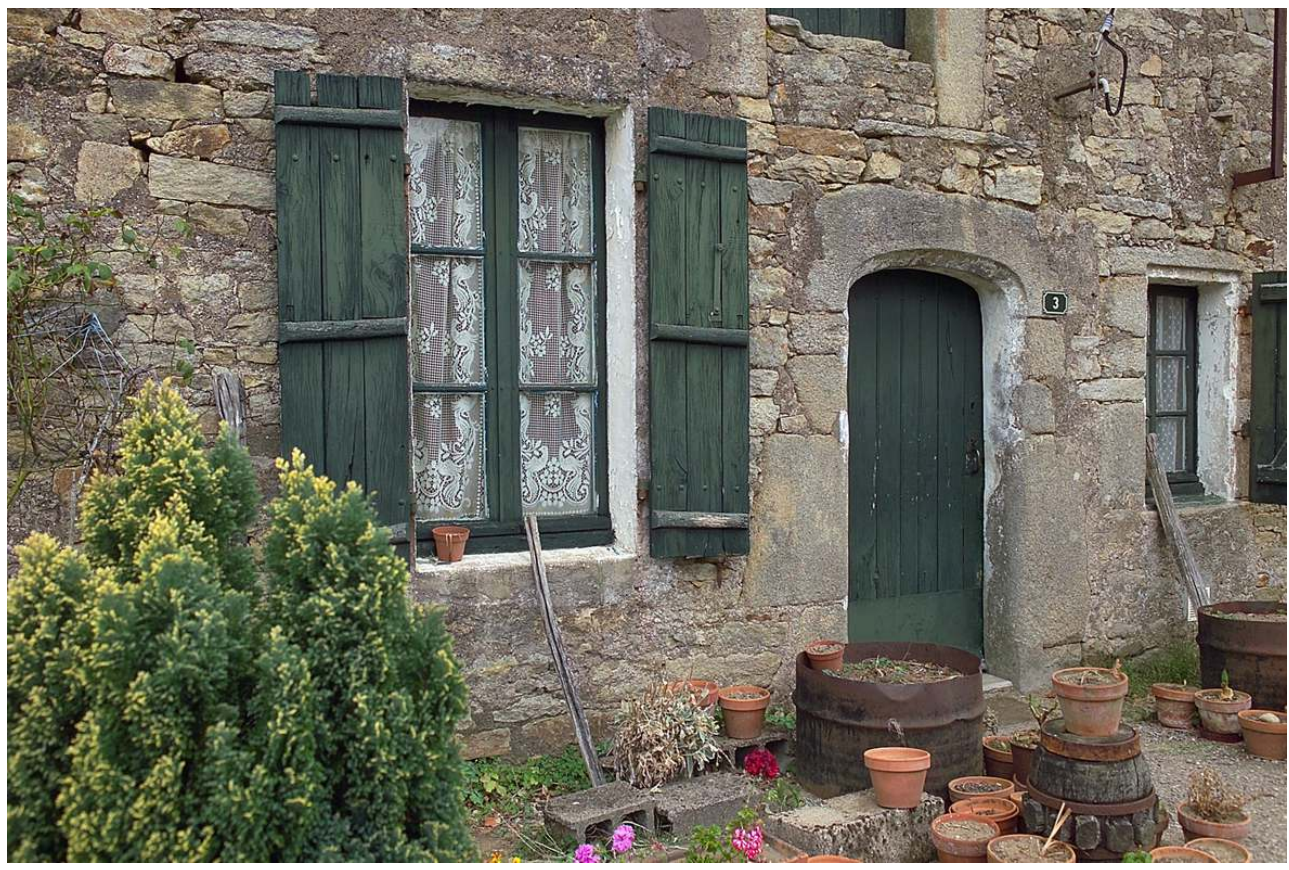

Vigneux-de-Bretagne (Loire-Atlantique), le Château. Logis paysan, 1679

(c) Inventaire général, région des Pays de la Loire

\section{Figure 22}

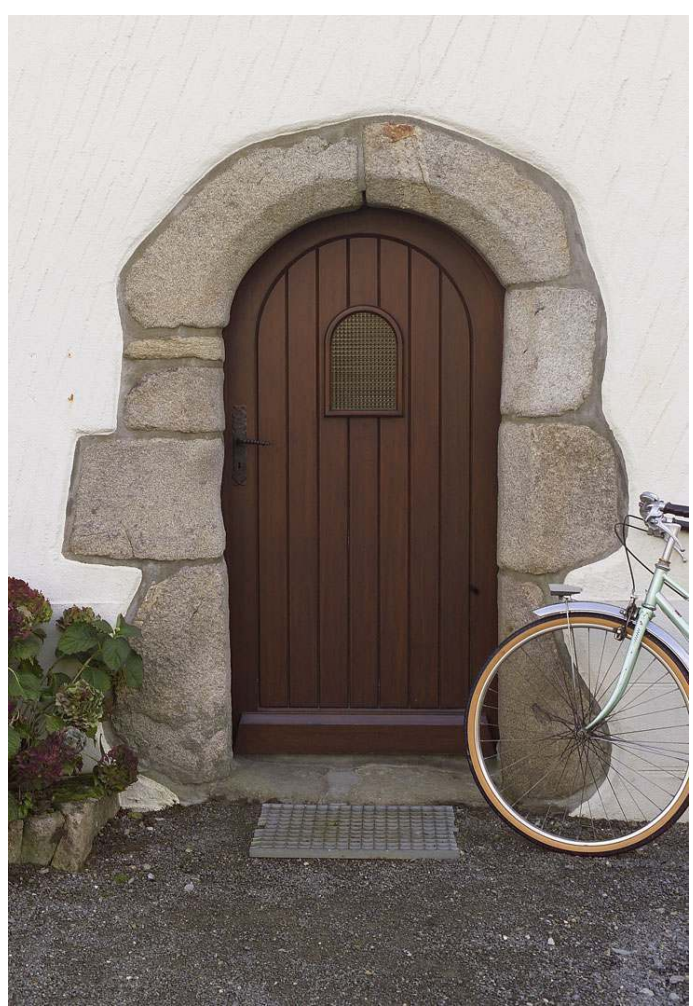

Saint-Lyphard (Loire-Atlantique), troisième ferme Kerjano. Porte (c) Inventaire général, région des Pays de la Loire 


\section{Critères techniques}

\section{La charpente}

Dans la région actuelle des Pays de la Loire, il faut distinguer trois secteurs qui reflètent des influences diverses :

- le Maine et l'Anjou, qui relevaient traditionnellement du domaine de la couronne de France;

- une très large partie de la Loire-Atlantique, qui manifeste des caractères comparables à ceux que l'on observe en Bretagne ;

- la Vendée et le sud de la Loire-Atlantique, territoire où domine la «maison latine », pour reprendre l'expression de J.-S. Gauthier.

\section{La Vendée et le sud de la Loire}

Dans cette région, la charpente est souvent difficile à dater, du fait du caractère rustique de sa confection (fig. $\mathbf{n}^{\circ}$ 23) : cette maison date du XIXe siècle, mais pourrait avoir été construite suivant les mêmes principes deux ou trois siècles plus tôt. Notons pour mémoire cet exemple de charpente dite " bordelaise » (fig. $\mathbf{n}^{\circ}$ 24) (maison à Saint-Jeande-Monts datant de la fin $d u X^{e}$ ou du début du XVI ${ }^{e}$ siècle), écho touchant des charpentes médiévales du nord de la Loire.

Figure 23

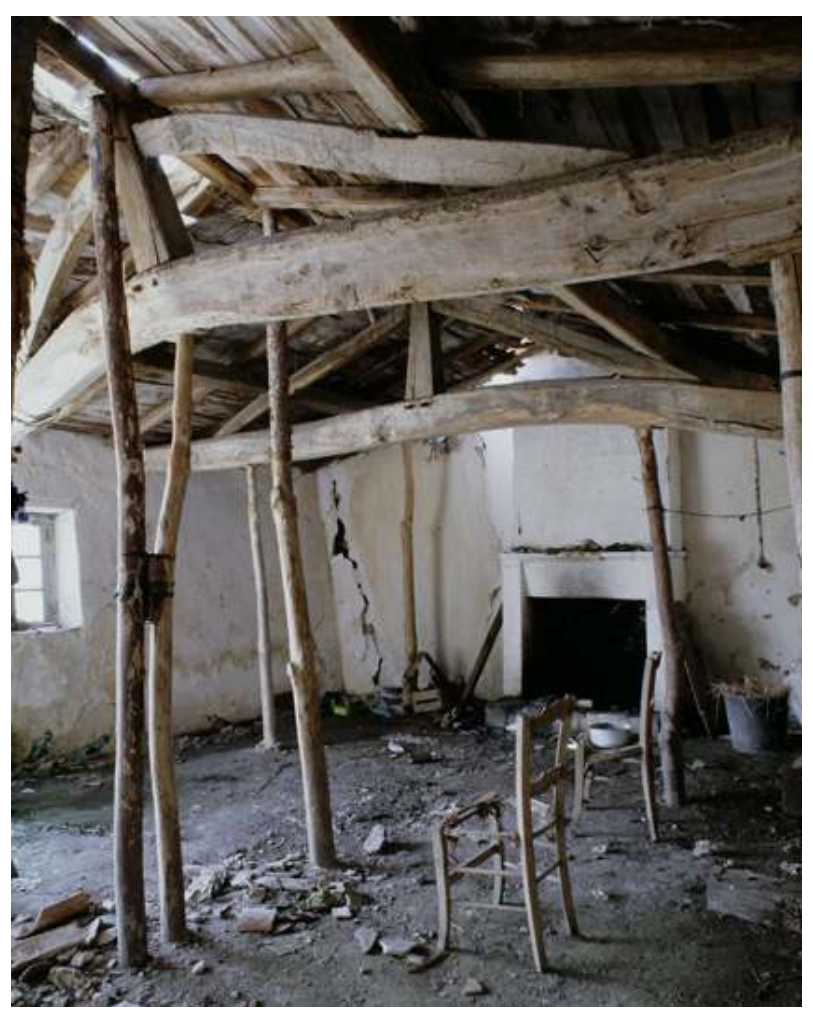

Notre-Dame-des-Monts (Vendée), le Cesson. Logis paysan, XIXe siècle (c) Inventaire général, région des Pays de la Loire 
Figure 24

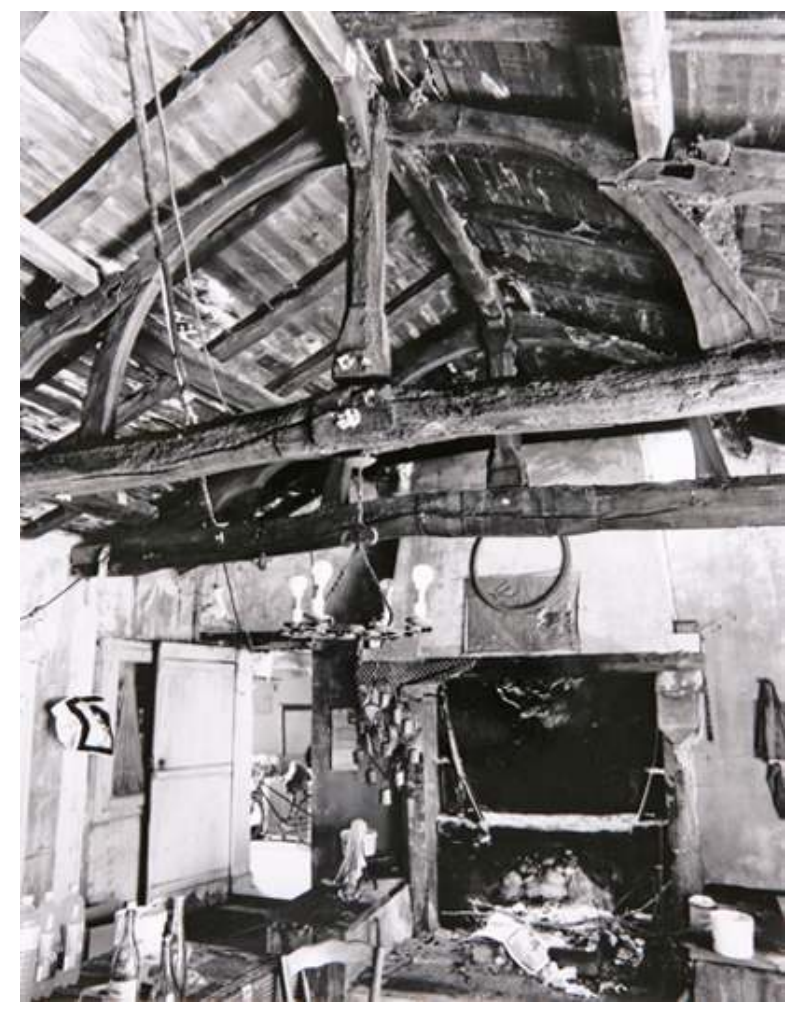

Saint-Jean-de-Monts (Vendée). Logis paysan, fin XVe-début XV|e siècles

(C) Inventaire général, région des Pays de la Loire

\section{Le « domaine royal »}

C'est dans ce secteur que la situation est la plus lisible. Jusqu'à la fin de la période médiévale, la charpente est systématiquement à chevrons portant ferme (fig. $\mathbf{n}^{\circ} \mathbf{2 5}$ ) (le Grand-Buisson à La Flèche). Par la suite, se généralise un type de charpente que je serais tenté de qualifier "d'intermédiaire», qui consiste à glisser une panne entre l'entrait retroussé et l'arbalétrier (fig. $\mathbf{n}^{\circ}$ 26) (les Noës à Solesmes). Entreprise dans les années 1990 par Marie Bardisa qui, dans le canton du Grand-Pressigny ${ }^{15}$ (Indre-et-Loire) a rencontré un grand nombre de charpentes de ce type, une étude dendrochronologique a mis en évidence une datation répartie dans la seconde moitié du XVI ${ }^{e}$ siècle. Toutefois, une récente analyse dendrochronologique, commandée par Christian Davy dans le canton de Sainte-Suzanne (Mayenne), a mis en évidence une charpente de ce type exécutée dès la toute fin du XV siècle. 
Figure 25

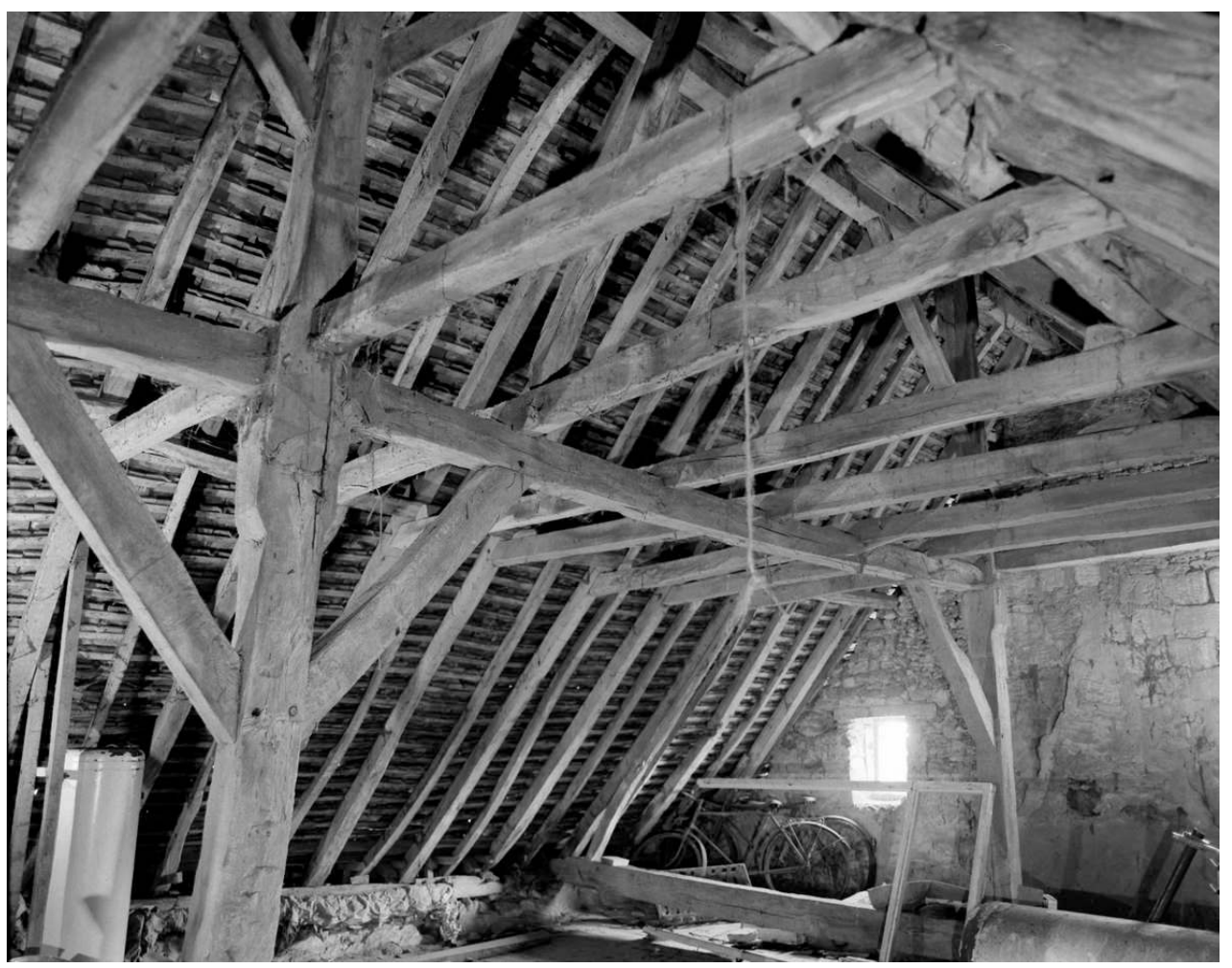

La Flèche (Sarthe), le Grand-Buisson. Charpente médiévale à chevrons portant ferme (c) Inventaire général, région des Pays de la Loire 


\section{Figure 26}

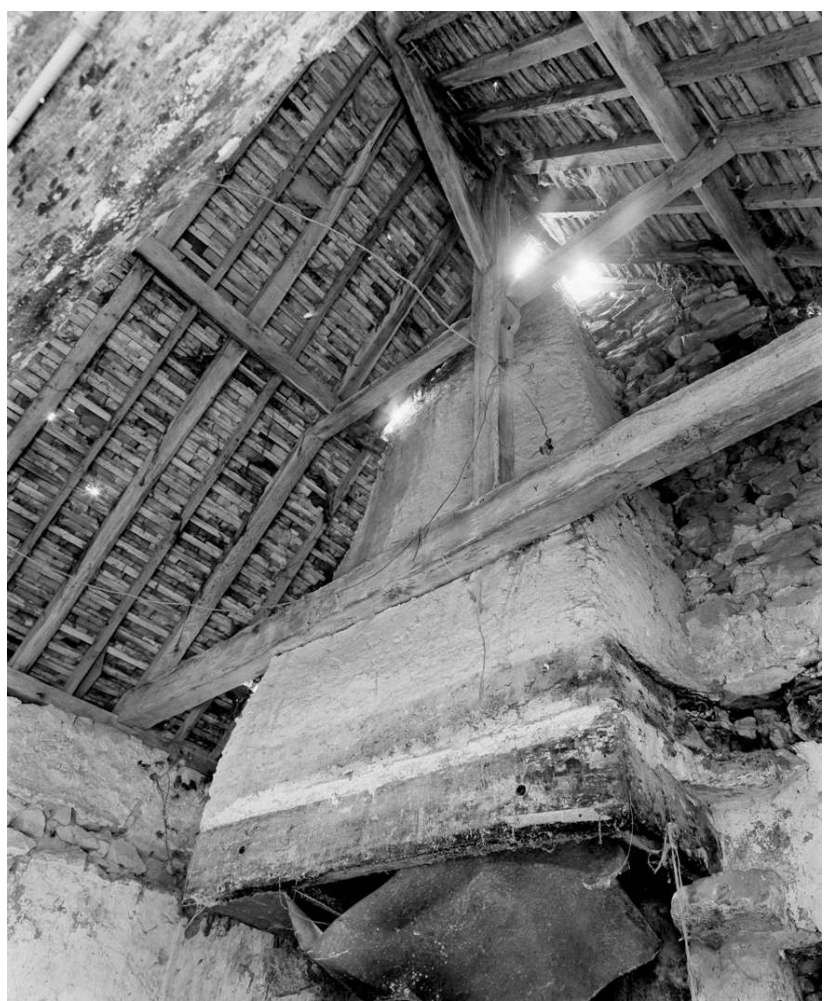

Solesmes (Sarthe), les Noës. Charpente « intermédiaire », seconde moitié du XVIe siècle (c) Inventaire général, région des Pays de la Loire 


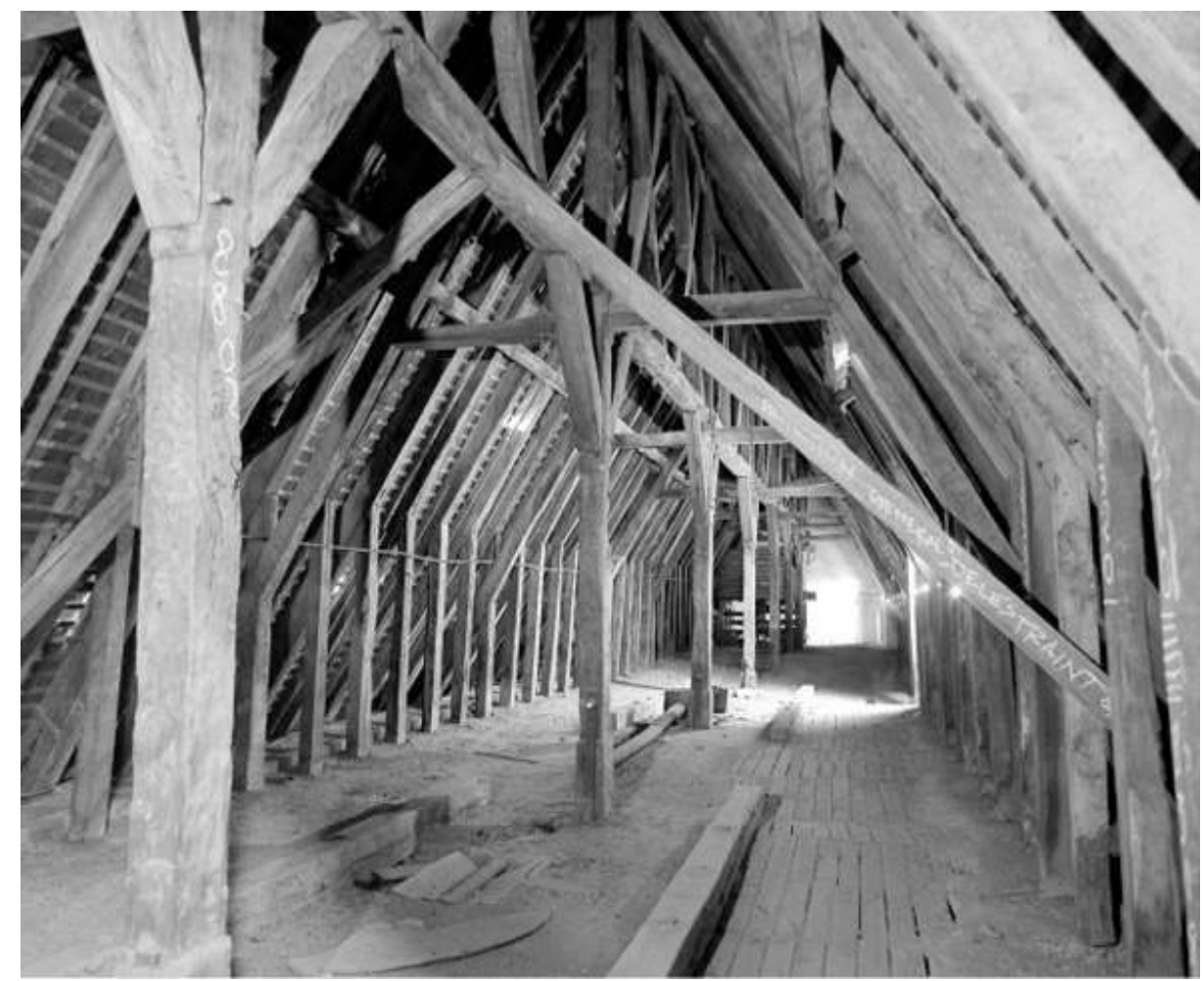

La Flèche (Sarthe), ancien collège des jésuites (Prytanée). Aile de la «cour des pensionnaires ». Charpente à pannes, XVIIe siècle

(c) Inventaire général, région des Pays de la Loire

La généralisation de la «véritable » charpente à pannes ne s'effectue, dans la grande région de Sablé/La Flèche, que dans le courant du XVII ${ }^{e}$ siècle, très certainement à la suite du prestigieux chantier du collège des jésuites de La Flèche, qui avait sollicité et formé nombre d'artisans de la région (fig. $\mathbf{n}^{\circ} \mathbf{2 7}$ ) (charpente d'une aile de la «cour des pensionnaires » du collège). Ces charpentes sont caractérisées par le soin apporté à leur confection, qui s'observe jusque dans les chantignoles ou tasseaux ${ }^{16}$, taillées en forme de cubes et consciencieusement assemblées à tenon et mortaise sur l'arbalétrier et le chevron se trouvant dans l'alignement de la ferme.

Très fréquemment repris dans la région, ce type de charpente présente l'avantage de constituer un repère chronologique relativement sûr: ferme du manoir de Coulon à La Chapelle-d'Aligné (fig. n 28), la Basse-Éturcie à La Flèche (fig. n²9). 
Figure 28

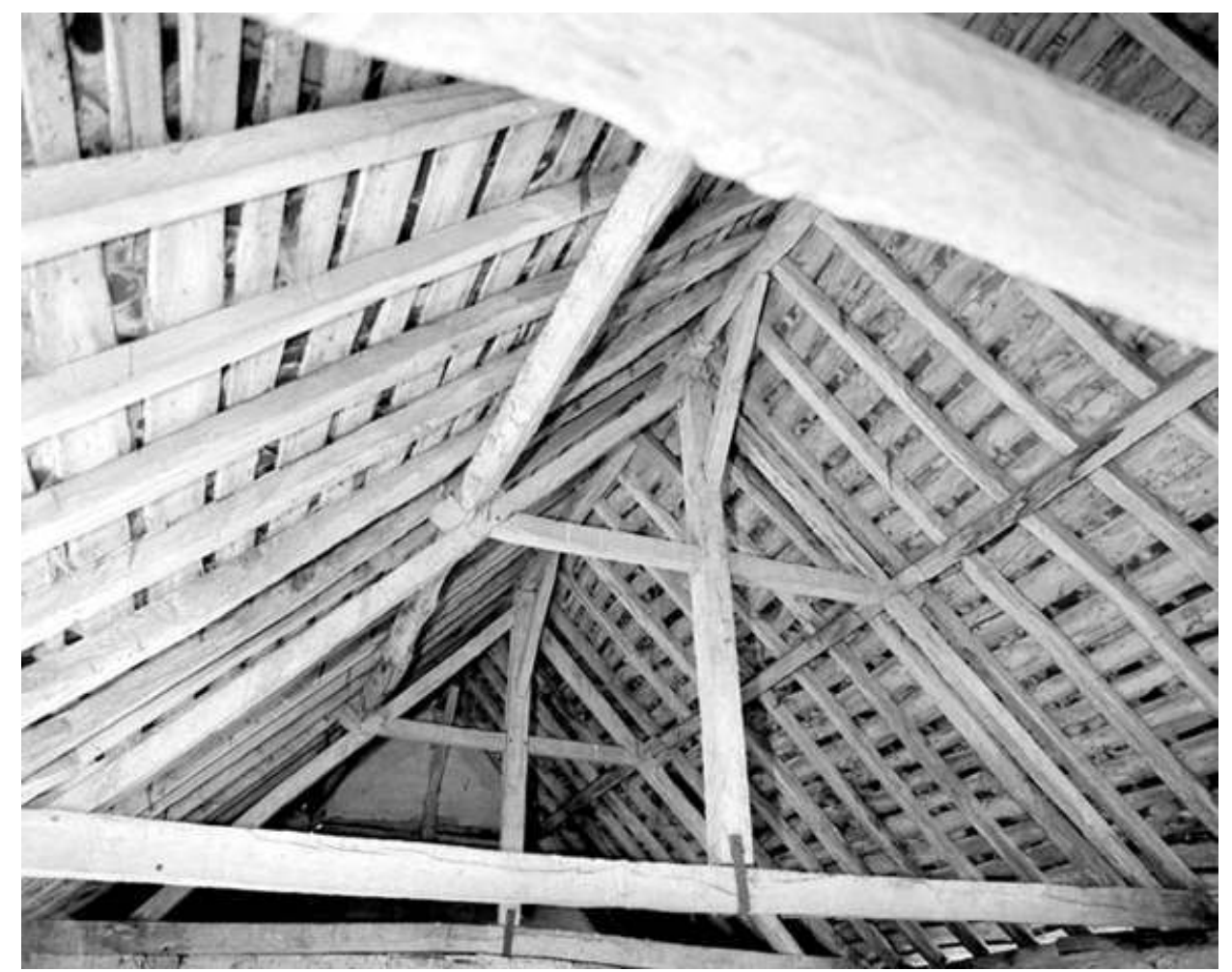

La Chapelle-d'Aligné (Sarthe), ferme du manoir de Coulon. Charpente à pannes, XVIIe siècle (c) Inventaire général, région des Pays de la Loire 
Figure 29

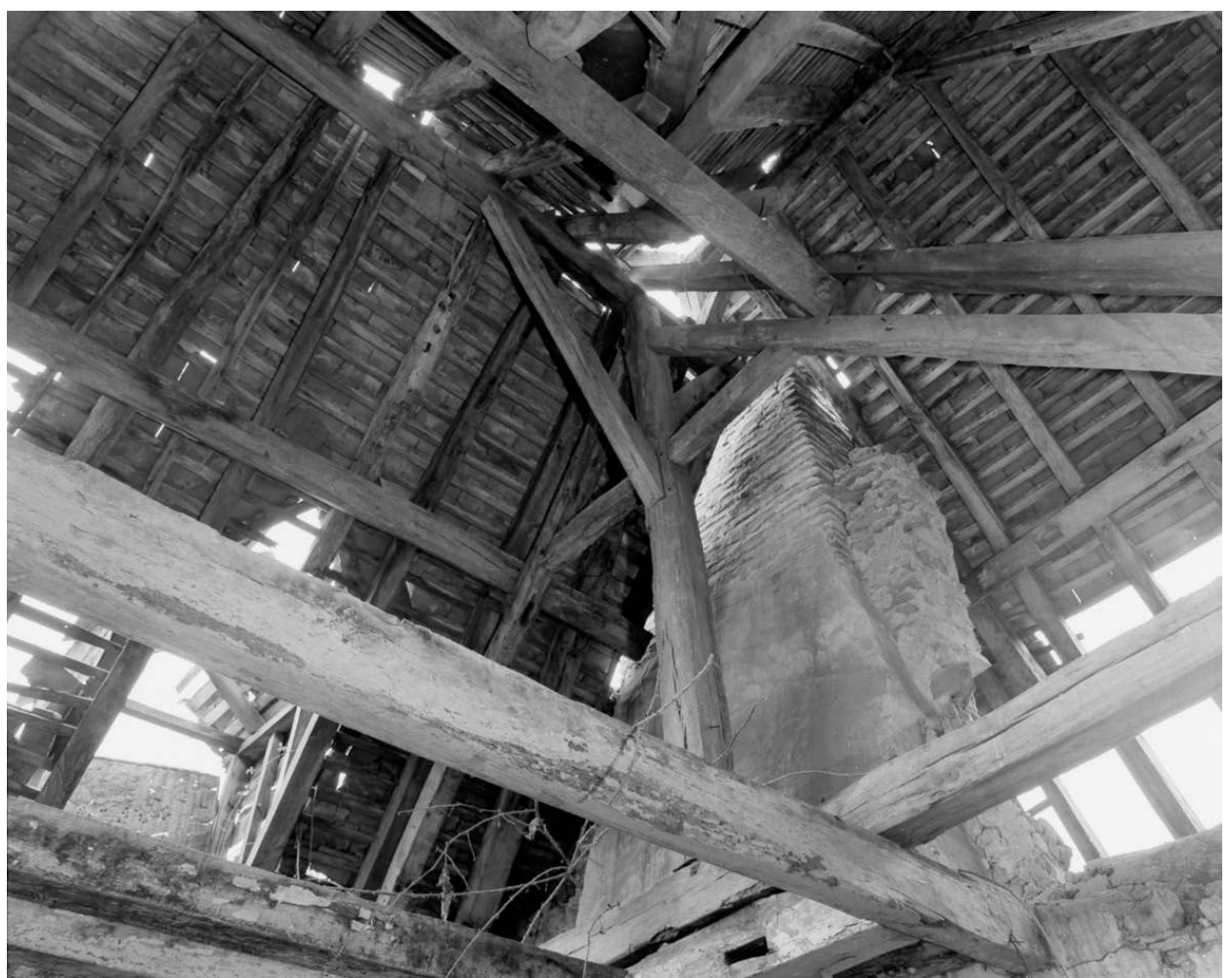

La Flèche (Sarthe), la Basse-Eturcie. Charpente à pannes, XVIIe siècle

(c) Inventaire général, région des Pays de la Loire

28 Mentionnons pour mémoire un autre type de charpente, d'un usage un peu plus récent, qui dérive d'une volonté de faciliter la circulation dans le comble, suivant une formule

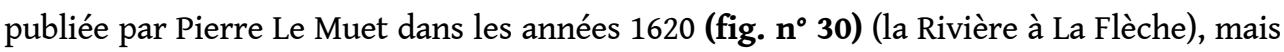
qui semble n'être apparue dans la région guère avant la seconde moitié du XVII ${ }^{\mathrm{e}}$ siècle. 
Figure 30

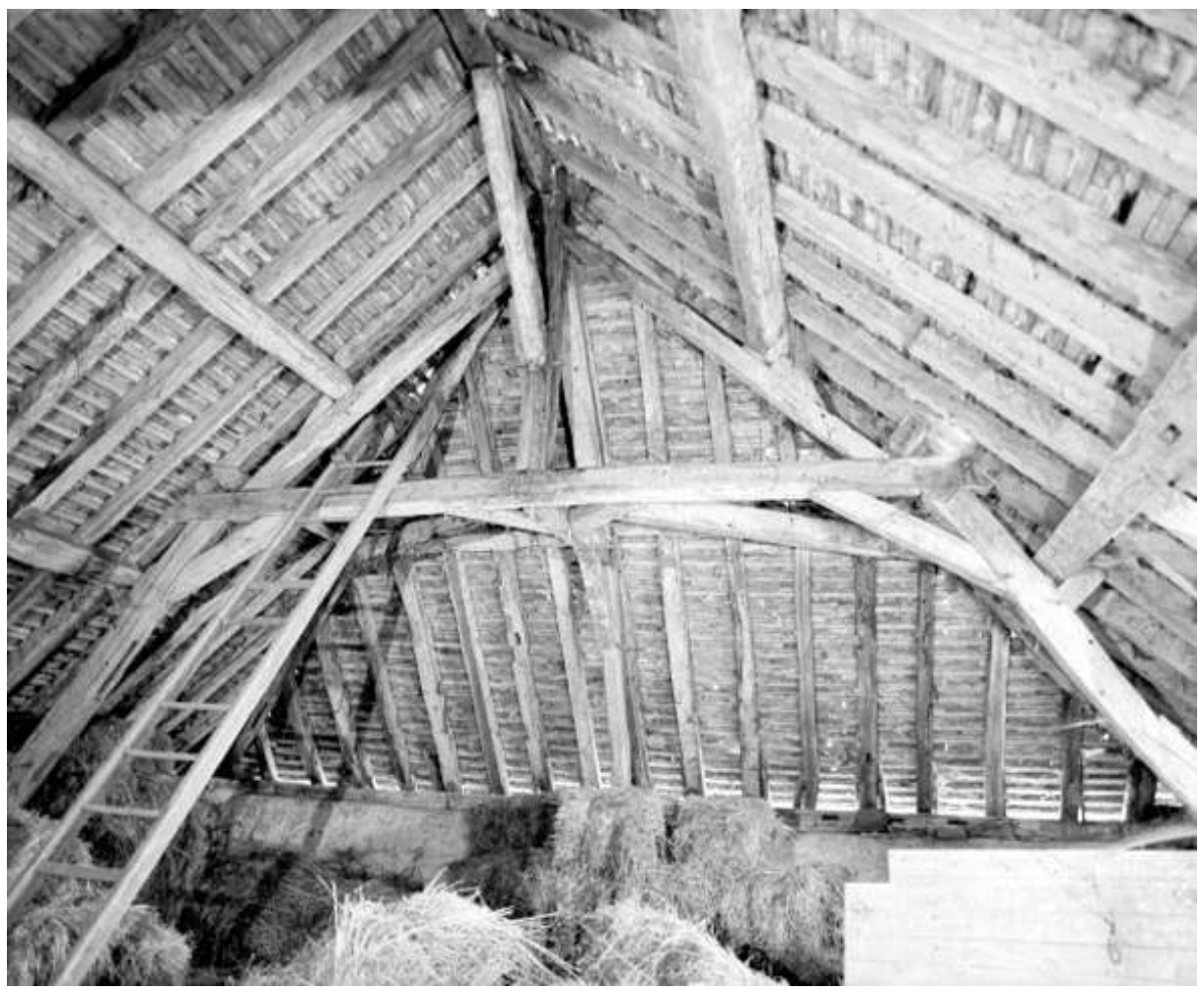

La Flèche (Sarthe), la Rivière. Charpente, seconde moitié du XVIIe siècle (c) Inventaire général, région des Pays de la Loire

\section{La Loire-Atlantique}


Figure 31

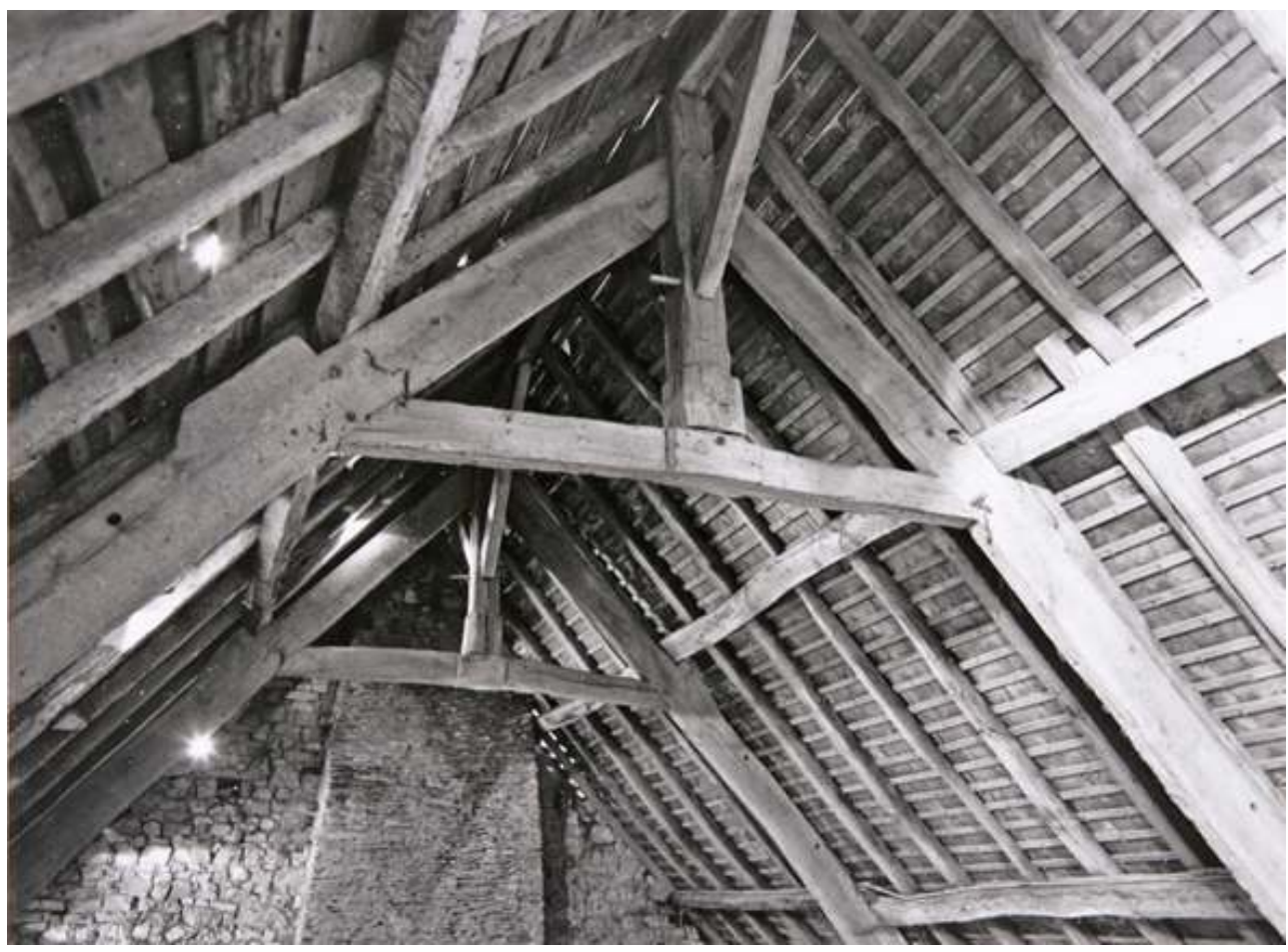

Villepôt (Loire-Atlantique), la Génauderie. Charpente à pannes, ferme à poinçon court, XVII siècle

(c) Inventaire général, région des Pays de la Loire

Le type de charpente rencontré dans cette région est en tout point comparable aux charpentes observées en Bretagne et en Grande-Bretagne. Ce sont des charpentes à pannes qui, par la force des choses, datent du XVII ${ }^{e}$ siècle (cf. supra) mais qui perpétuent un modèle fréquemment rencontré dans l'architecture savante de l'époque médiévale. Les pannes sont fixées sur les arbalétriers au moyen d'encoches taillées dans ces derniers ; la ferme est caractérisée par ailleurs par son poinçon court reliant le faîtage et un entrait retroussé (fig. $\mathbf{n}^{\circ}$ 31) (la Génauderie à Villepôt), qui seconde l'entrait inférieur posé sur le sommet des murs du surcroît (non visible sur la photo).

L'importance du volume du comble est liée à la capacité de production de l'exploitation agricole car, dans la presqu'île guérandaise, région moins prospère que le nord du département, l'entrait inférieur est appelé à jouer un double rôle : raidir la ferme d'une part, mais aussi servir de poutre pour porter le plancher (fig. $\mathbf{n}^{\circ}{ }^{32}$ ) (Kertrait à SaintLyphard et Ménac à Saint-Joachim). 
Figure 32
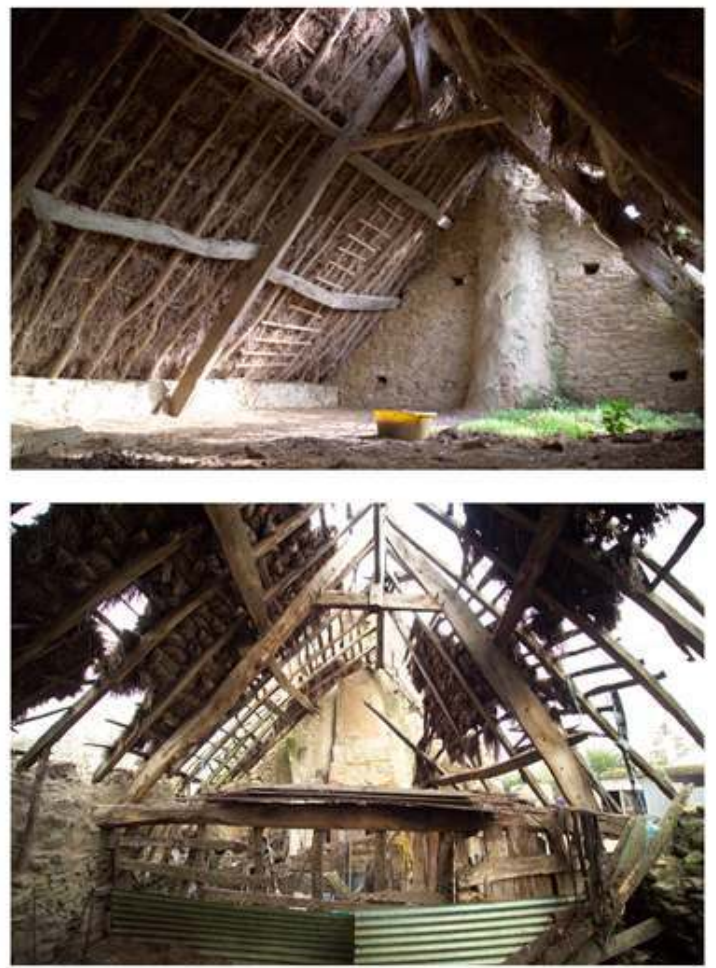

Saint-Lyphard (Loire-Atlantique), Kertrait : charpente à pannes, XVIIe siècle ; Saint-Joachim (LoireAtlantique), Ménac : charpentes à pannes, XVIIe siècle

(c) Inventaire général, région des Pays de la Loire

Figure 33

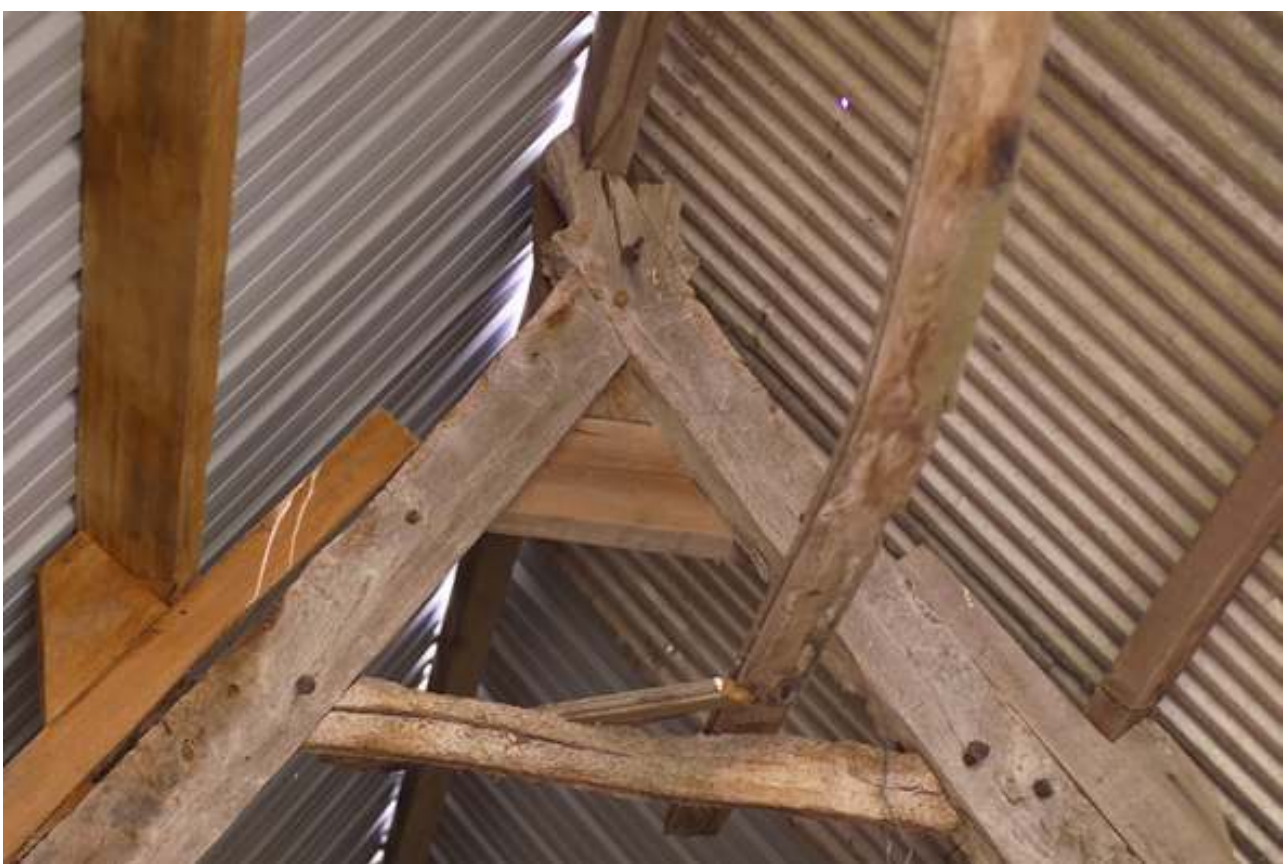

Saint-Lyphard (Loire-Atlantique), Kerado. Charpente d'une resserre (c) Inventaire général, région des Pays de la Loire 
31 quelques types de charpentes (majoritairement rencontrés sur des corps de dépendance mais observés aussi sur certains logis ${ }^{17}$ ) qui frappent par l'archaïsme de leur mise en œuvre. Dans cette resserre briéronne, (fig. $\mathbf{n}^{\circ}$ 33) si l'on a fait l'économie du poinçon, l'entrait retroussé est en revanche bien en place. On notera surtout le type d'assemblage à mi-bois des arbalétriers, dont le croisement permet de porter la panne faîtière.

\section{Le mortier}

L'usage de la terre comme mortier semble caractériser le bâti rural ancien (c'est-à-dire antérieur au XIX ${ }^{e}$ siècle) dans les Pays de la Loire (fig. $\mathbf{n}^{\circ}$ 34) (pignon en Brière), toutes régions confondues ${ }^{18}$. À Châteaubriant, des raisons économiques expliquent sans doute une évidente réticence à utiliser la chaux malgré la présence sur place, dans les années 1530, de deux fours à chaux installés à l'occasion de la reconstruction du château, et qui ne serviront que pour cet édifice.

Figure 34

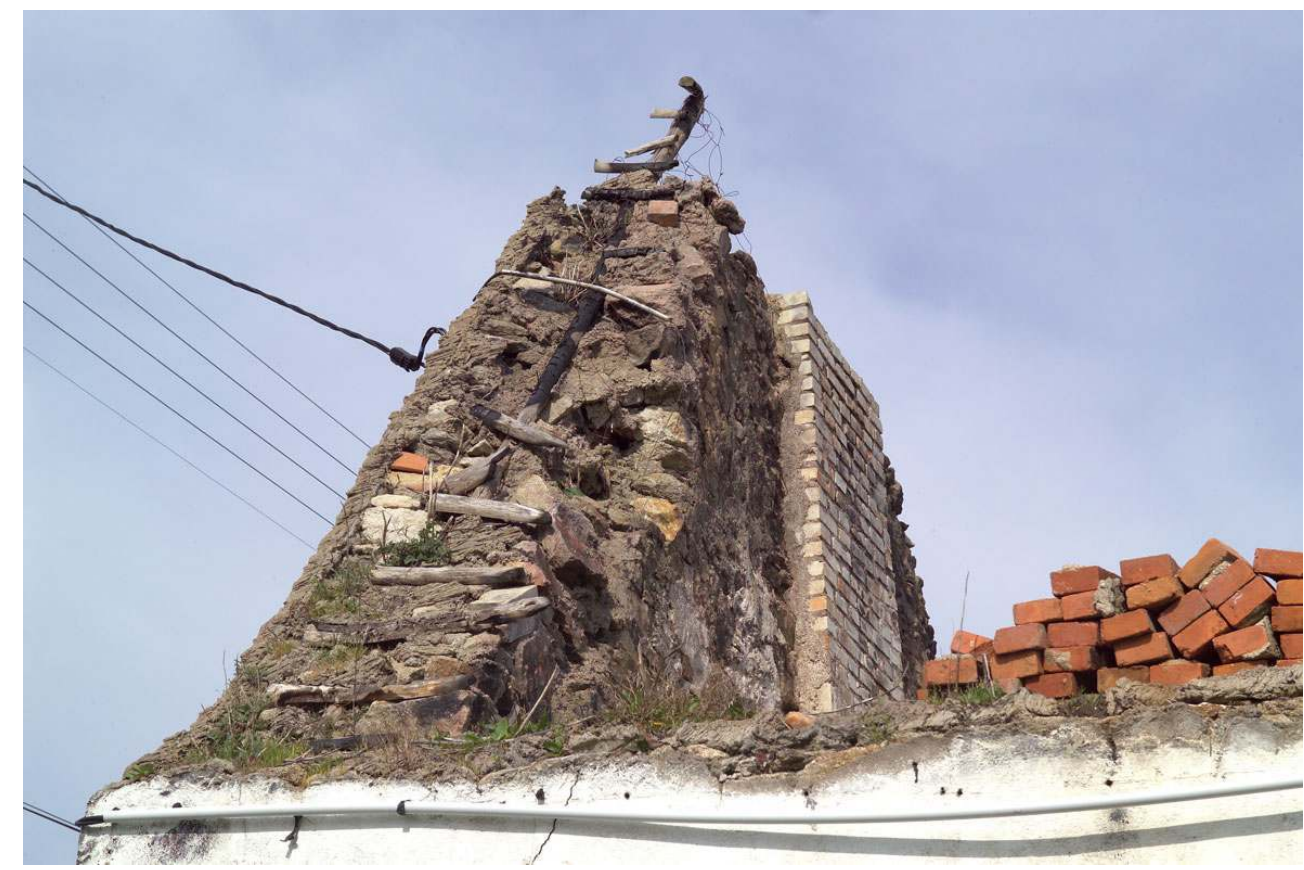

Saint-Joachim (Loire-Atlantique), Fédrun. Pignon à mortier de terre

(C) Inventaire général, région des Pays de la Loire

Le recours à la chaux semble avoir été plus précoce dans le Maine et l'Anjou, provinces décidément les plus «modernes » de la région. Toutefois, s'il m'a été donné de retrouver plusieurs marchés de construction de logis ruraux aux XVII ${ }^{\mathrm{e}}$ et $\mathrm{XVIII}{ }^{\mathrm{e}}$ siècles, qui recommandaient (peut-être à la faveur d'une formule notariale toute faite) une construction « à chaux et à sable », je n'ai jamais eu l'occasion de vérifier son usage sur le terrain. 


\section{Critères structurels : le plan de la maison}

\section{La « maison longue »}

34 À la suite de G. Meirion-Jones ${ }^{19}$, nous comprendrons sous cette appellation un logis où cohabitent hommes et animaux dans un même espace. Ce type d'habitat ne subsiste aujourd'hui, à l'état résiduel, qu'en Brière et dans la presqu'île guérandaise (véritable conservatoire d'archaïsmes), dans des bâtiments dont les plus anciennes constructions ne semblent pas remonter au-delà du XVII ${ }^{e}$ siècle. Je n'ai retrouvé aucun indice ailleurs dans les Pays de la Loire ${ }^{20}$ : peut-être, dans ces régions, cette structure fut-elle abandonnée à l'occasion de la « révolution » de la maçonnerie?

Conduites pendant la dernière guerre, les enquêtes sur l'architecture rurale ont montré que ces « maisons longues » étaient particulièrement nombreuses, dans des proportions qui sont sans commune mesure avec les vestiges encore identifiables aujourd'hui. Ce sont souvent les bâtiments en ruine qui, paradoxalement, sont les plus lisibles (fig. $\mathbf{n}^{\circ} \mathbf{3 5}$ ) (Ménac à Saint-Joachim, dans un logis qui porte le millésime 1615, dégagé par hasard à la faveur de la ruine du logis voisin à gauche). À La Chapelle-des-Marais, le logis de Québitre (fig. $\mathbf{n}^{\circ}$ 36) avait été repéré en bon état dans les années 1940. Le relevé effectué alors (fig. $\mathbf{n}^{\circ}$ 37) met en évidence la crèche des animaux, qui constitue la seule séparation entre l'étable et la pièce habitable, qui ne mesure pas plus d'un demi-mètre de hauteur.

Figure 35

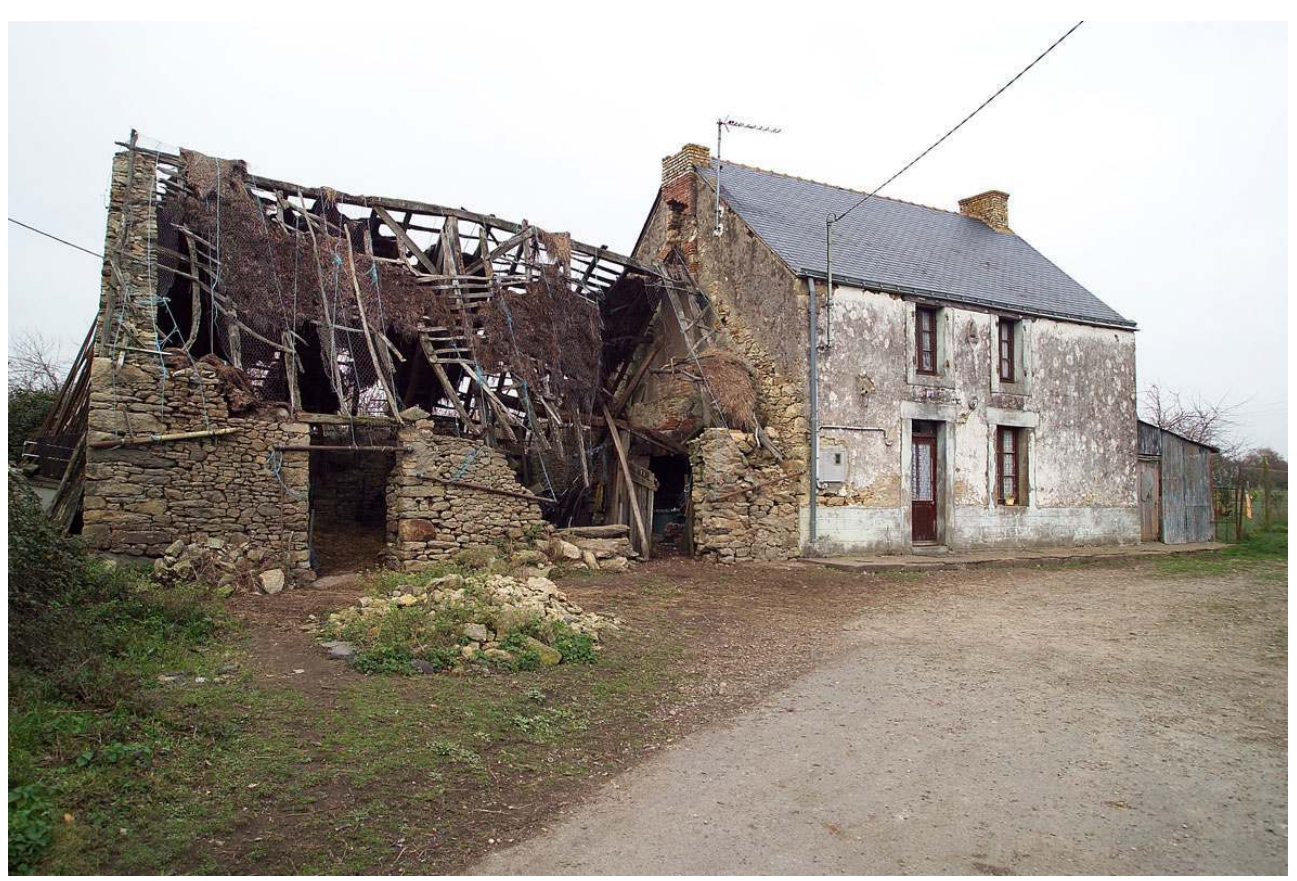

Saint-Joachim (Loire-Atlantique), Ménac. « Maison longue », 1615

(C) Inventaire général, région des Pays de la Loire 
Figure 36

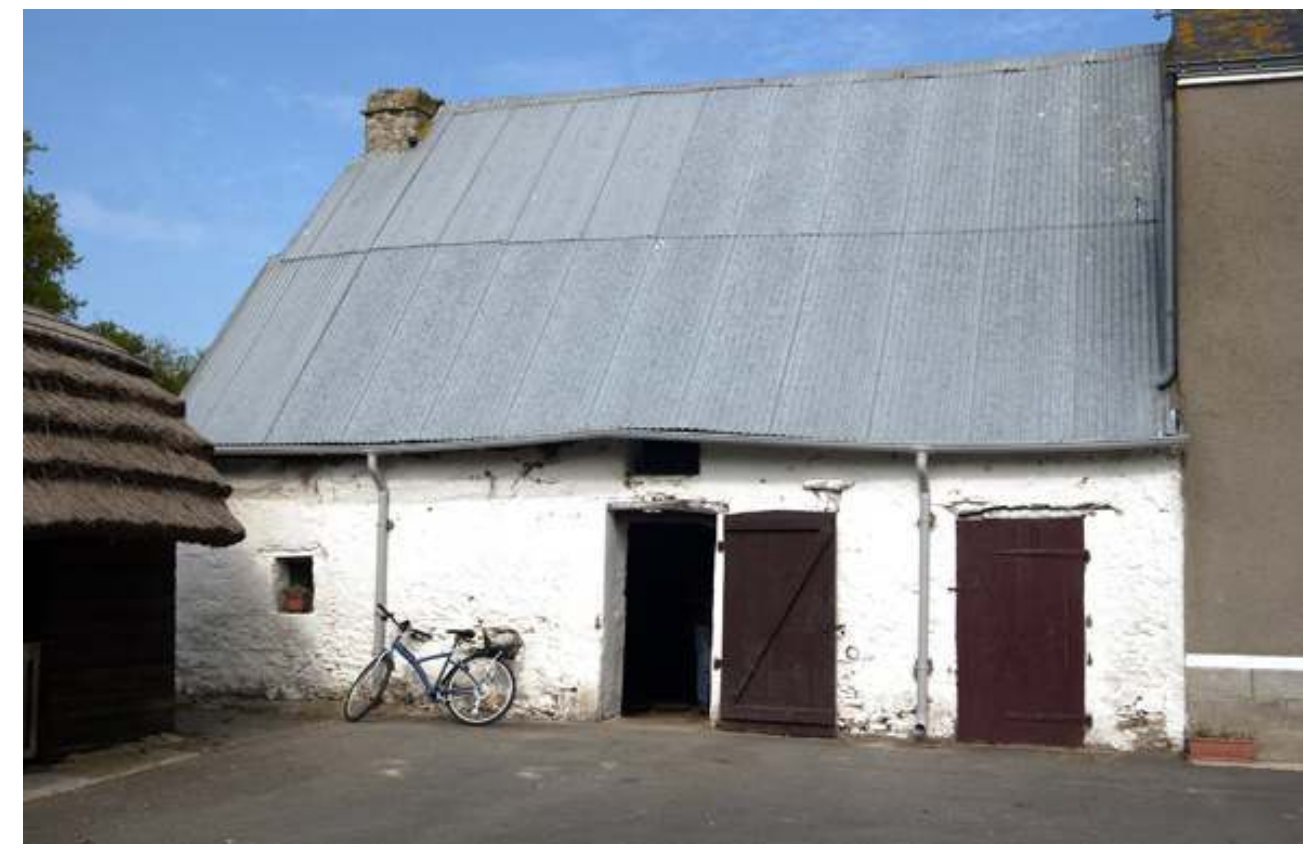

La Chapelle-des-Marais (Loire-Atlantique), Québitre. « Maison longue »

(C) Inventaire général, région des Pays de la Loire

Figure 37

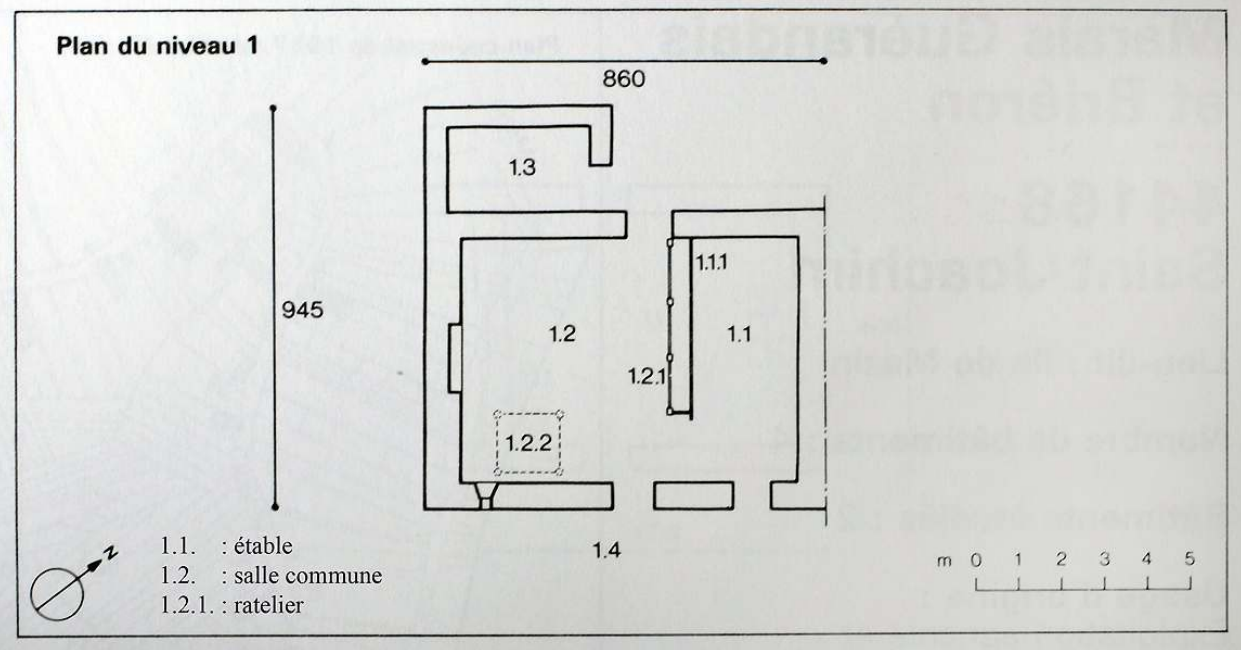

La Chapelle-des-Marais (Loire-Atlantique), Québitre. « Maison longue », plan

(c) Inventaire général, région des Pays de la Loire 


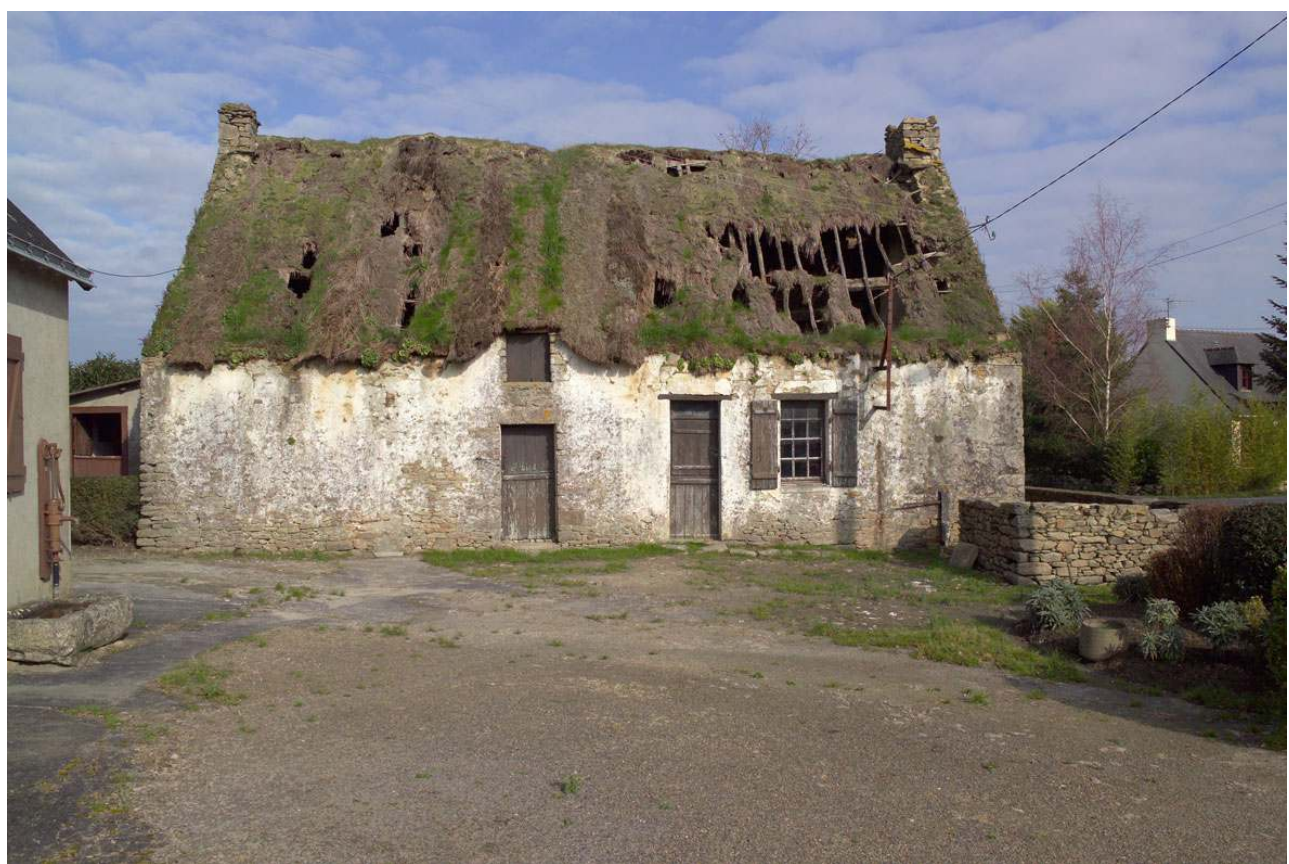

Saint-Lyphard (Loire-Atlantique), Kertrait. « Maison longue », 1678

(c) Inventaire général, région des Pays de la Loire

Le logis de Kertrait, à Saint-Lyphard (fig. $\mathbf{n}^{\circ}$ 38), revêt un intérêt tout particulier. Il s'agit d'une ancienne "maison longue », qui portait autrefois la date de 1678, digne de foi, semblerait-il, dont la partie habitable, à droite, exception faite de la cheminée (fig. $\mathbf{n}$ - 39), a été remaniée dans les années 1920 (élargissement des ouvertures et surtout pose d'une cloison en bois entre l'étable et la pièce (fig. $\left.\mathbf{n}^{\circ} \mathbf{4 0}\right)$ où, par chance, la crèche a été conservée. Mais on notera surtout la présence d'une souche de cheminée factice au sommet du pignon de l'étable, répondant à un souci évident de symétrie : étonnante collision entre archaïsme et préoccupations issues de l'esthétique de la Renaissance ${ }^{21}$. 
Figure 39

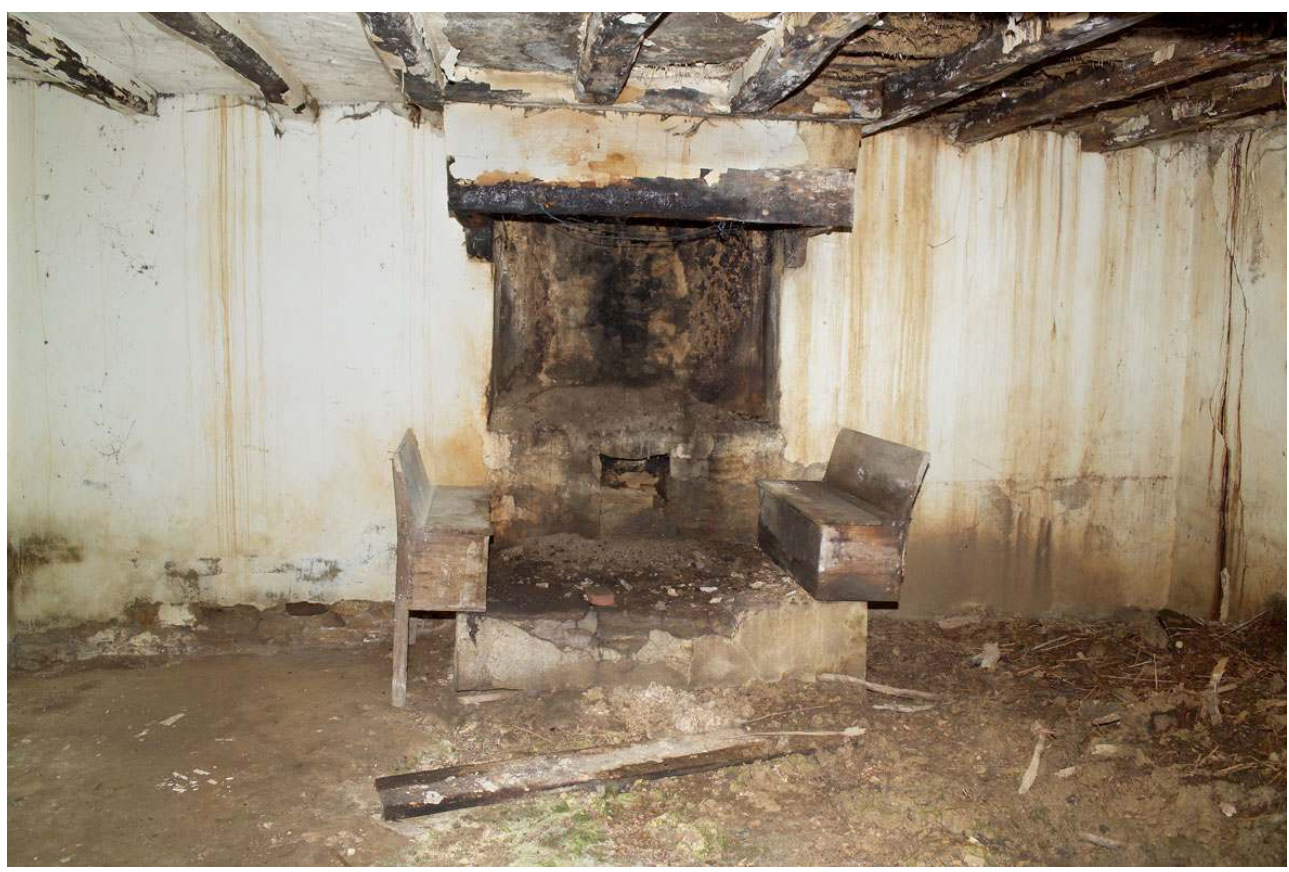

Saint-Lyphard (Loire-Atlantique), Kertrait. Salle commune

(c) Inventaire général, région des Pays de la Loire

Figure 40

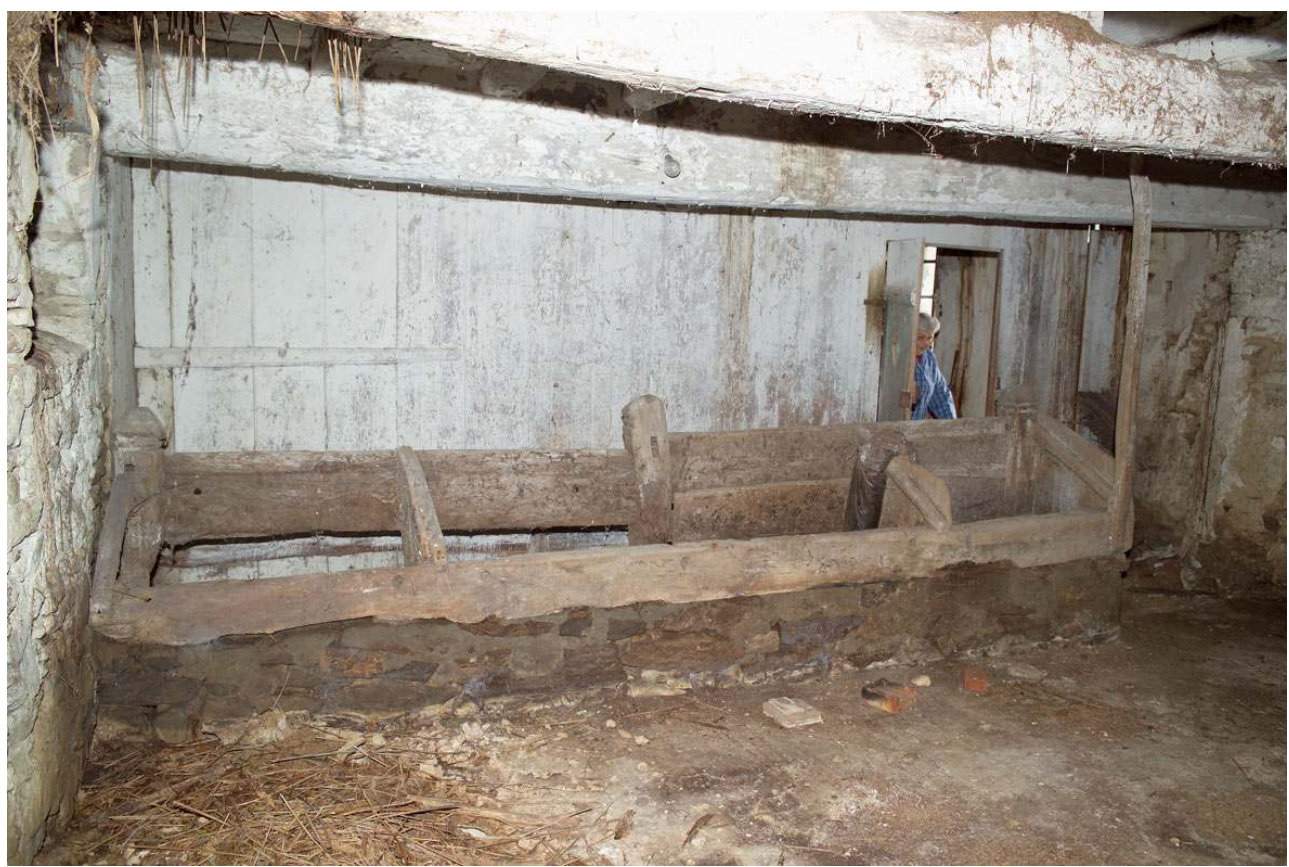

Saint-Lyphard (Loire-Atlantique), Kertrait. Crèche ancienne, cloison de séparation réalisée au XXe siècle (c) Inventaire général, région des Pays de la Loire 


\section{Le logis mixte}

37 La disposition des logis mixtes ne diffère des précédents que par la présence d'un mur de refend - la plupart du temps en maçonnerie - qui sépare définitivement l'étable de la pièce habitable. C'est le cas de la ferme de l'Homme à Ruffigné, près de Châteaubriant (fig. $\mathbf{n}^{\circ}$ 41), logis « banalisé » construit dans le courant du XVIII ${ }^{e}$ siècle.

Figure 41

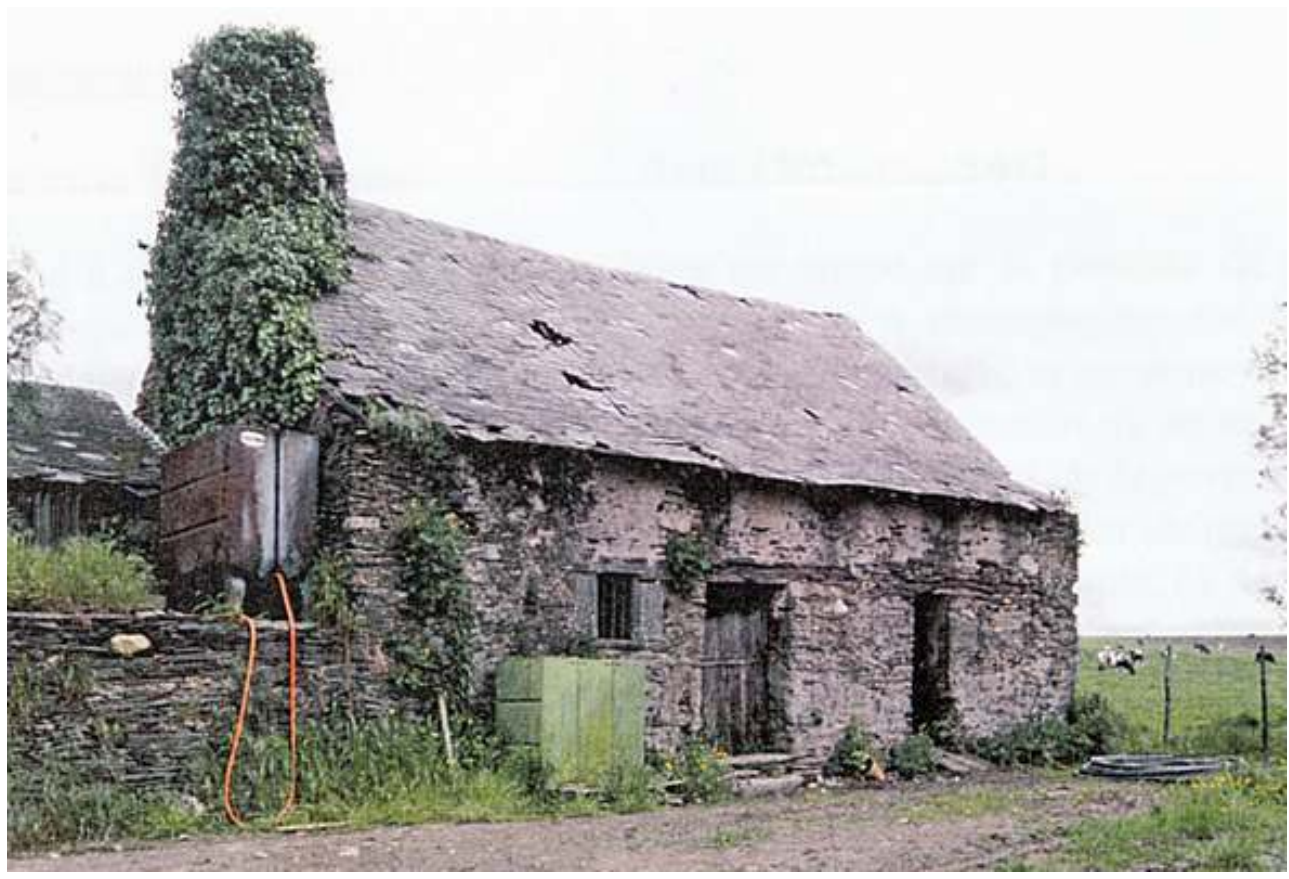

Ruffigné (Loire-Atlantique), L'Homme. Logis mixte, XVIIIe siècle

(c) Inventaire général, région des Pays de la Loire

38 Cette disposition est très généralisée dans le Maine et en Anjou (fig. $\mathbf{n}^{\circ}$ 42) (plan-terrier de la Guaisserie à La Chapelle-d'Aligné) : « l'étable » et la «maison » sont séparées par le mur sans aucune communication intérieure. 


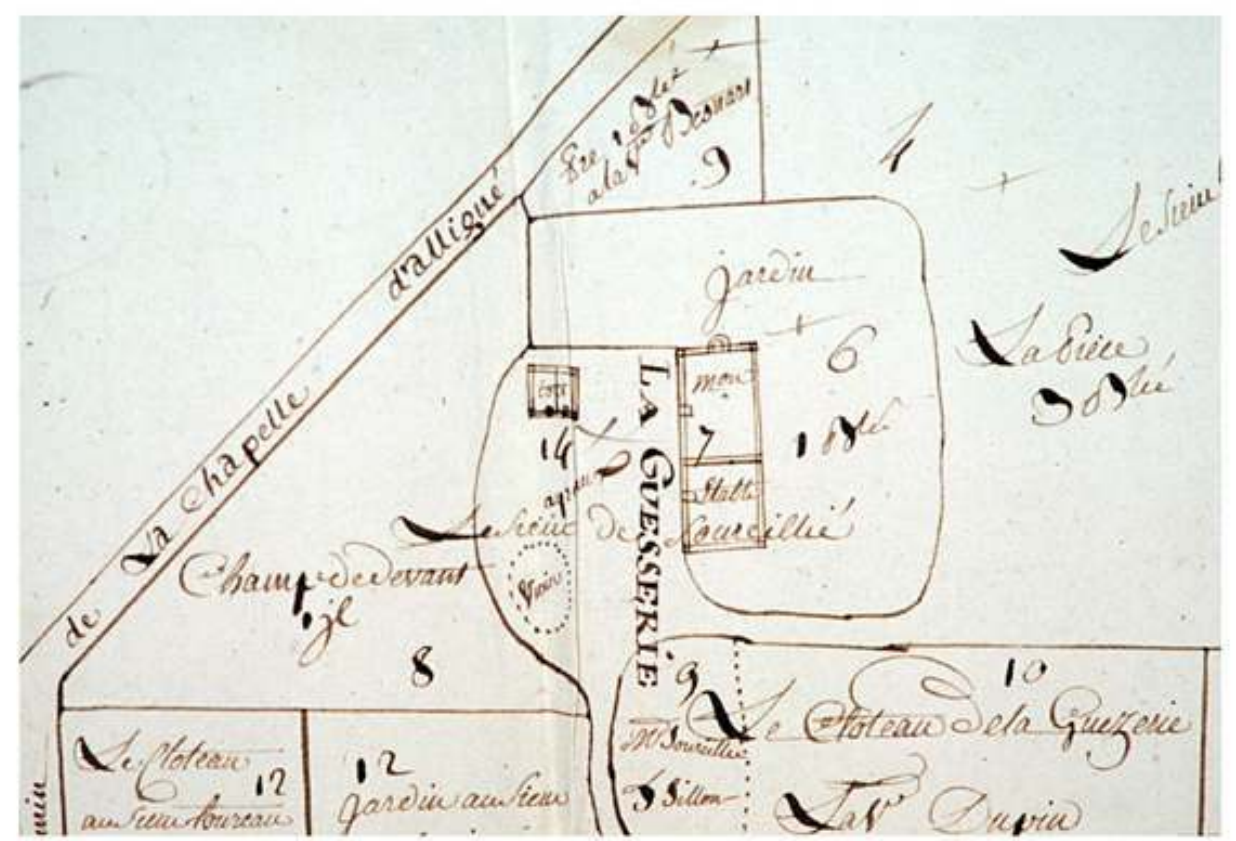

(A.D. Maine-et-Loire, $285 \mathrm{H} 38$ )

La Chapelle-d'Aligné (Sarthe), la Guaisserie. Plan-terrier (A.D. Maine-et-Loire, 285 H 38)

(c) Inventaire général, région des Pays de la Loire

\section{Le logis « double »}

Il s'agit d'une appellation non garantie, que Michel Nassier et moi-même étions convenu d'adopter pour désigner des logis comportant deux pièces habitables contiguës, dans la région de Châteaubriant, mais qui pourrait s'appliquer également à nombre de logis du Maine (les Noës à Solesmes) (fig. $\mathbf{n}^{\circ} \mathbf{4 3}$ ), longère du XVI ${ }^{e}$ siècle, dont la façade se lit de gauche à droite, cheminée, fenêtre et porte de la "pièce à feu ", puis fenêtre isolée éclairant une pièce "froide ", qui, dans le meilleur des cas, ne sera dotée d'une cheminée que dans le courant du XIX siècle et enfin l'étable, distribuée par une porte qui lui est propre ; à Lognonnet, Auvers-le-Hamon (fig. $\mathbf{n}^{\circ} \mathbf{4 4}$ ), près de Sablé, la même lecture est tout simplement inversée, de droite à gauche : " pièce à feu ", « pièce froide », étable. 
Figure 43

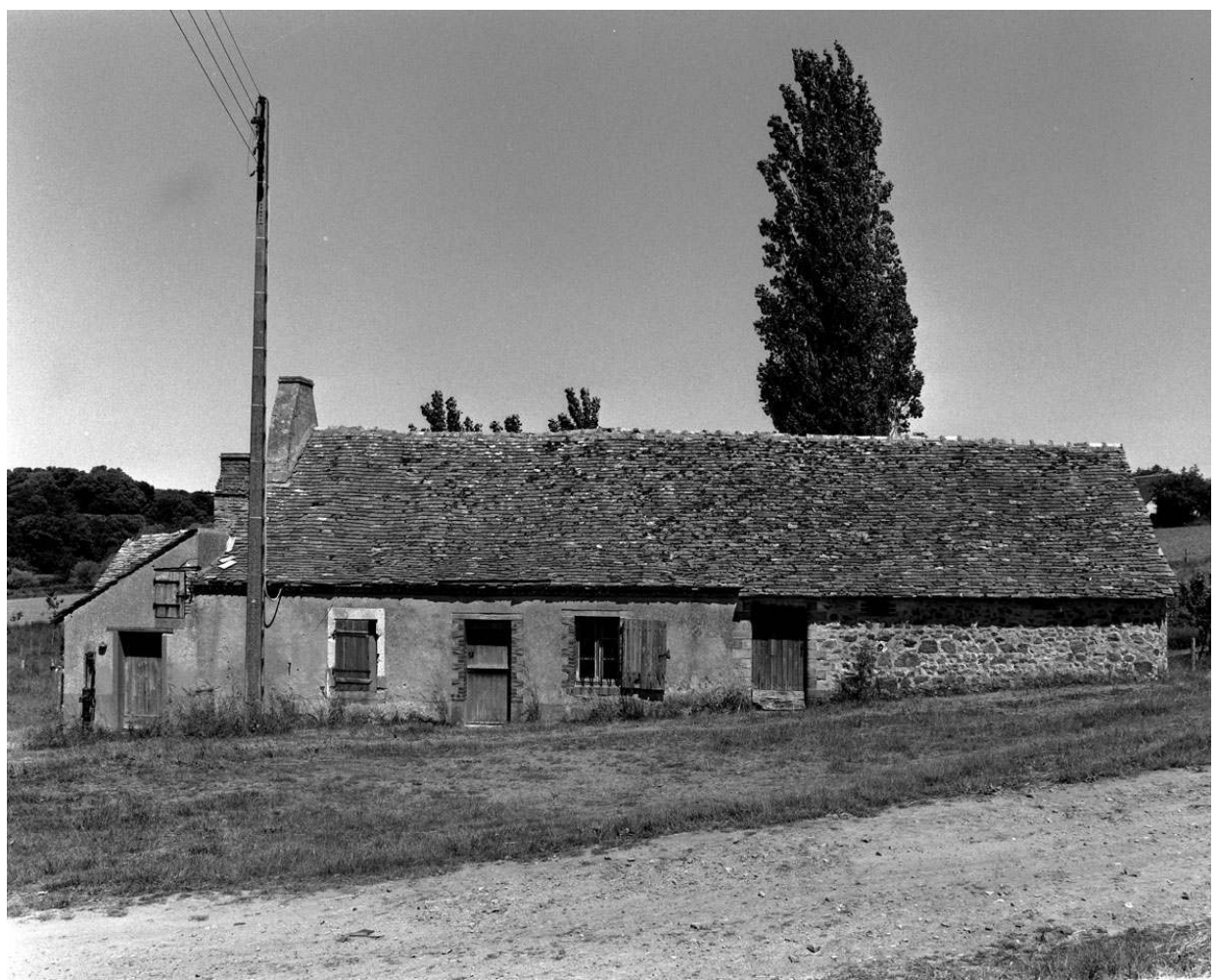

Solesmes (Sarthe), les Noës. Longère, XV|e siècle

(C) Inventaire général, région des Pays de la Loire 
Figure 44

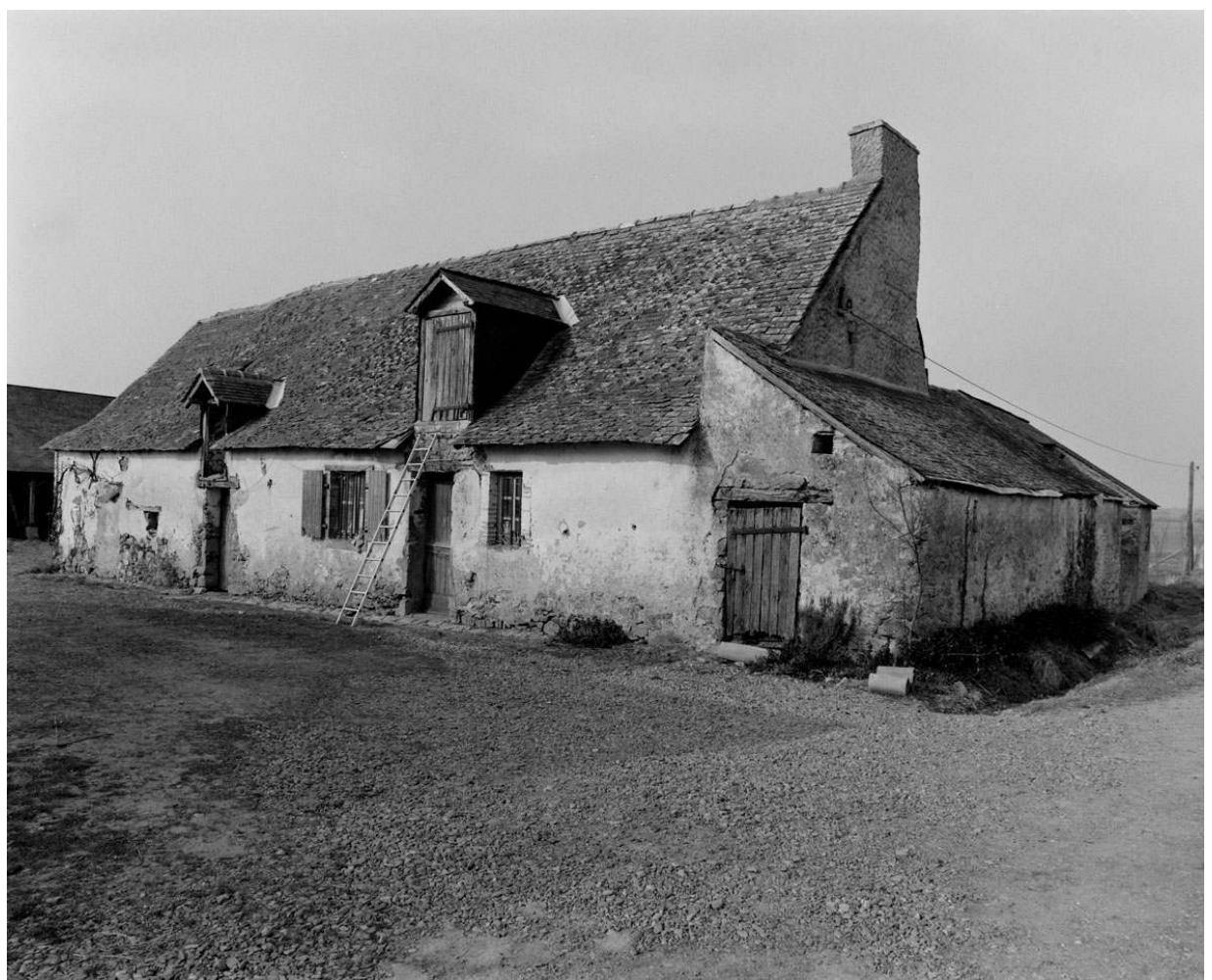

Auvers-le-Hamon (Sarthe), Lognonnet. Logis « double »

(c) Inventaire général, région des Pays de la Loire

Dans les bourrines du marais breton vendéen, on retrouve une structure assez proche, quoique généralement beaucoup plus tardive, au XIX et au début du XXe ${ }^{\mathrm{e}}$ siècle $^{22}$ (fig. $\mathbf{n}$ -45) (la Tite-Bourrine à Notre-Dame-de-Monts). 


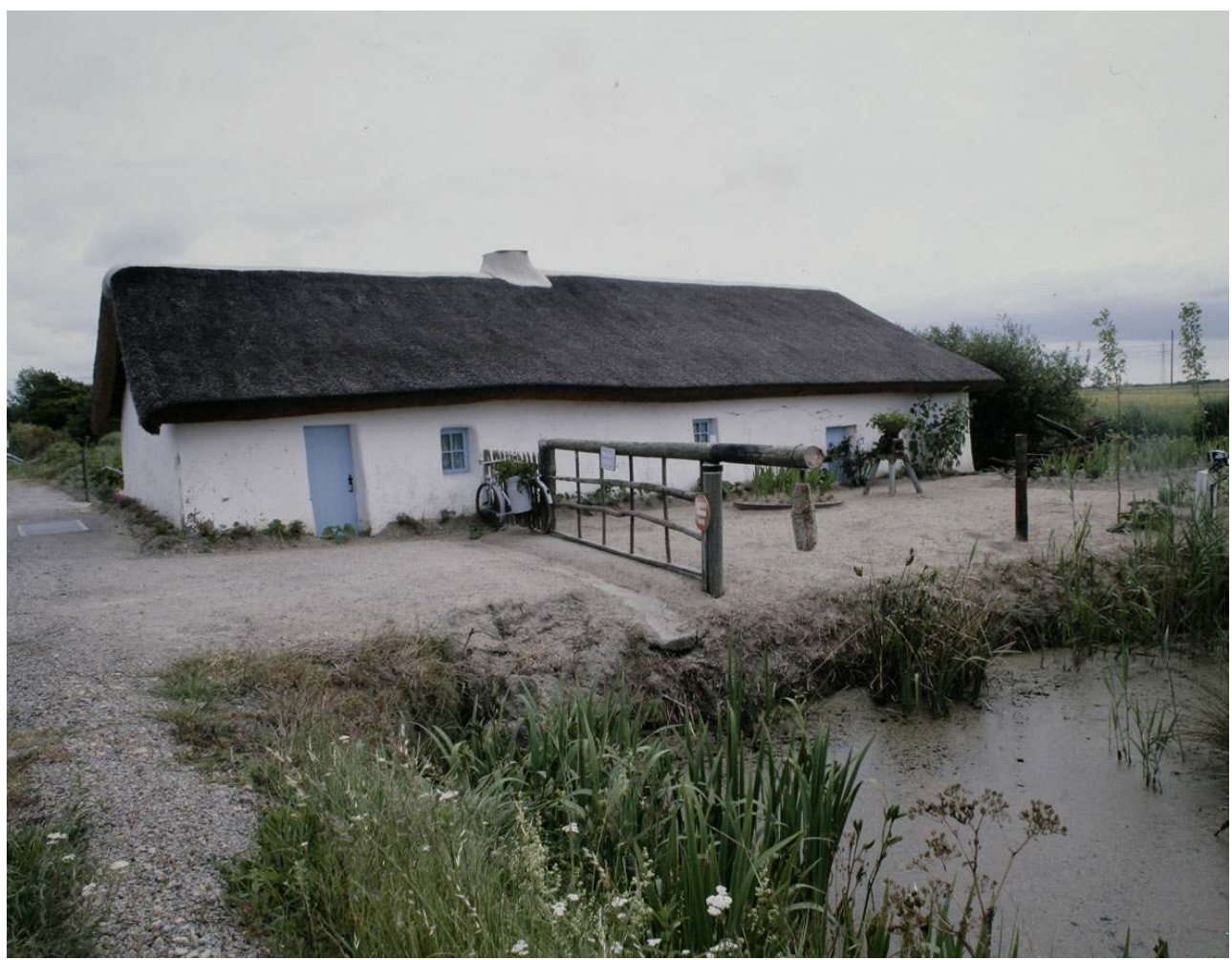

Notre-Dame-de-Monts (Vendée), la Tite-Bourrine. Logis « double», fin XIXe-XXe siècles (C) Inventaire général, région des Pays de la Loire

Dans le nord de la Loire-Atlantique, cette même structure s'observe dans un grand nombre des logis construits dans le courant du XVII ${ }^{e}$ siècle, évoqués ci-dessus. Désignée par la documentation sous le terme de " chauffe-pied ", la pièce à cheminée voisine avec une " chambre ${ }^{23}$ ", accessible par sa propre porte, plus modeste que la porte principale, et éclairée par un petit jour (la Génauderie à Villepôt) (fig. $\mathbf{n}^{\circ}$ 46). Au Mortier à Noyal-surBrütz, la communication entre les deux pièces se faisait à l'intérieur). Nous ne pouvons qu'être frappé par l'aspect peu pratique de cet espace exigu (il atteint rarement deux mètres en largeur), qui, malgré son appellation - dont le caractère pompeux dérive assurément du modèle du manoir -, ne peut en aucun cas être dévolu à un usage d'habitation. De fait, cette « chambre » sert généralement de resserre. 


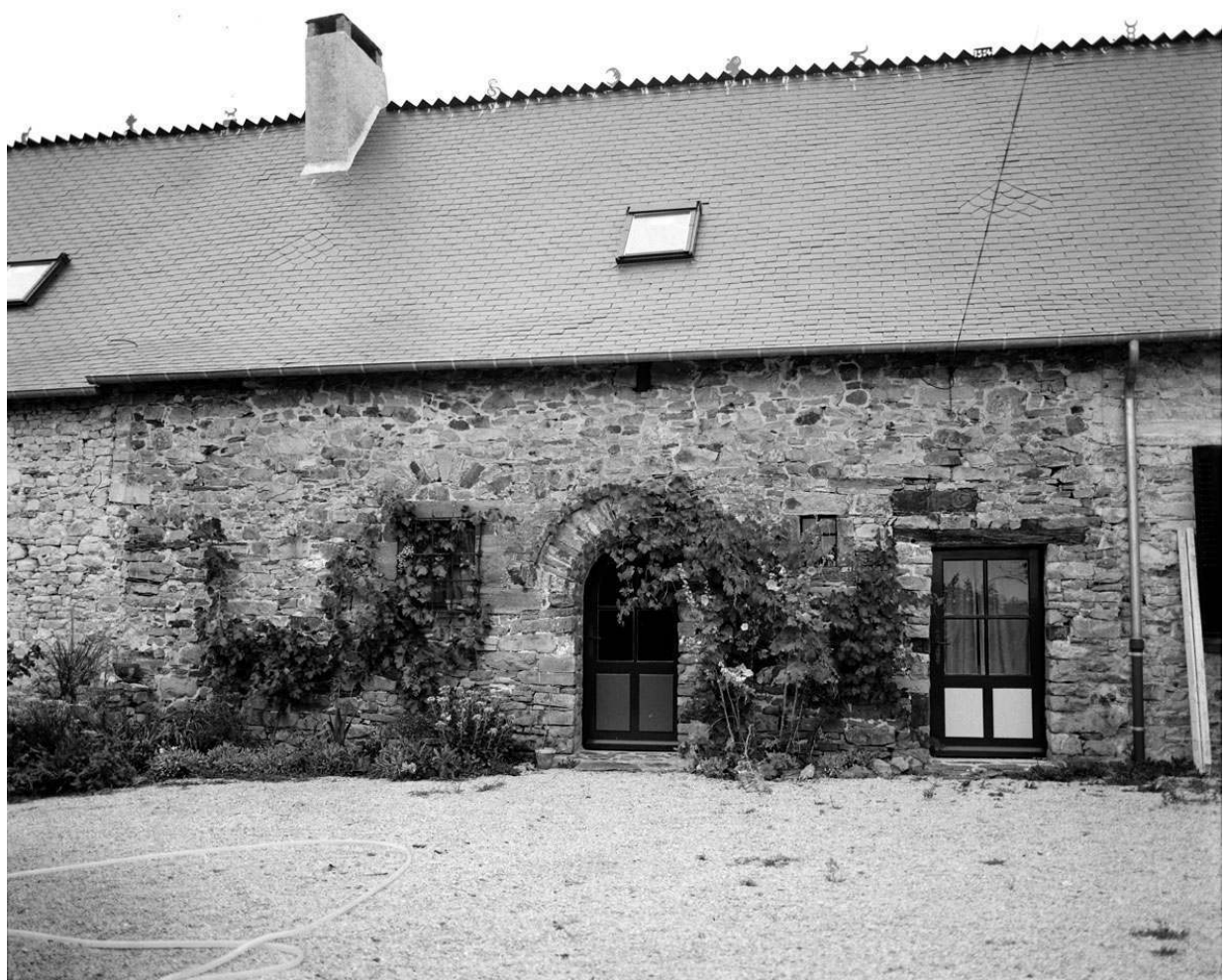

Villepôt (Loire-Atlantique), la Génauderie. Logis « double », XVIIe siècle

(c) Inventaire général, région des Pays de la Loire

\section{Conclusion}

42 Au terme de l'évocation des critères susceptibles de nous aider à situer dans le temps l'évolution de la maison paysanne, force est de conclure au caractère aventureux, ou tout au moins relativement imprécis, d'une telle approche. Le parcours se présente semé d'embûches, du fait des risques toujours possibles de remplois, de la permanence de certains archaïsmes, du voisinage ponctuel d'un édifice «phare » perturbant le paysage bâti d'une région, la moindre information se devant d'être impérativement passée au crible de la critique.

Cette approche présente néanmoins d'indéniables avantages, dans la mesure où elle nous invite à envisager la demeure paysanne sous divers angles. Les remarques que j'ai été amené à formuler à propos de la cheminée et de la composition de certaines façades notamment renvoient à des préoccupations qui paraissent bien éloignées du caractère strictement fonctionnel dans lequel on se complait trop volontiers à enfermer la maison paysanne. Amenant au contraire à s'interroger sur les usages de cette maison, la méthode invite à en questionner le programme. Et, chemin faisant, nous ne pouvons que constater que les éléments conditionnant les choix formels de cette maison ne diffèrent pas vraiment de ceux qui régissent l'architecture savante. La distinction entre ces deux formes d'expression architecturale ne paraissant pas évidente il est par conséquent très tentant d'en proposer une approche à partir de critères d'analyse communs. 


\section{NOTES}

1. Cette communication a été présentée dans le cadre de la formation organisée par la Direction de l'architecture et du patrimoine et par le service de l'inventaire général du patrimoine culturel de la Région Lorraine, sur le thème des Repères chronologiques pour la compréhension de l'architecture rurale, Saint-Dié-des-Vosges, mai 2006.

2. Demoyon, Albert. La maison picarde au XIX ${ }^{\mathrm{e}}$ siècle (rien n'y est donné au bien-être, au superflu, tout s'y dispose pour le travail agricole). Dans : Jean Dolfuss, Jean-Marie Pérez. Histoire de la vie privée, p. 440. (en réalité, les exemples de ce type sont légion).

3. Delpire, Laurent. Maisons couvertes en goémon au Croisic. Les Cahiers du Pays de Guérande, 2005.

4. Perouse de Montclos, Jean-Marie. Histoire de l'architecture française de la Renaissance à la Révolution. Paris : Mengès / CNRS, 1989, p. 26-27. Mussat, André. Arts et culture de Bretagne, un millénaire. Paris : Berger-Levrault, 1979.

5. Chapelot, Jean, Fossier, Robert. Le village et la maison au Moyen Âge. Paris : Hachette, 1980. Référence qui ne préjuge pas les nombreuses publications ultérieures.

6. Rykwert, Joseph. La Maison d'Adam au Paradis. Paris : Seuil, 1976.

7. A.C. Châteaubriant. On retiendra que seuls la cheminée et son conduit sont en pierre.

8. Fouilles de Pen-er-Malo, dans les années 1970, suivies de beaucoup d'autres chantiers, en Bretagne notamment.

9. Le Couedic, Daniel, Trochet, Jean-René. Bretagne l'architecture rurale française. Paris : Berger-Levrault, 1985, p. 154-155.

10. Les archéologues de Sablé-sur-Sarthe Claude Lambert et Jean Riouffreyt ont développé de telles hypothèses en étudiant des loges repérées en Anjou et en Touraine.

11. Gauthier, Joseph-Stany. Les maisons rurales de la Loire-Atlantique. Congrès de l'Association bretonne et Union régionaliste bretonne (1950). Folklore de la Loire-Inférieure $1^{\text {ère }}$ partie l'habitat, 1956.

12. Meirion-Jones, Gwyn. Le foyer en Bretagne. Mémoires de la Société historique et archéologique de Bretagne (1995), p. 335-347, (1996), p. 339-398.

13. Je reconnais que ma sélection d'images n'est pas très explicite sur ce point, exception faite de la Génauderie (le millésime 1606 est le plus ancien que j'ai repéré), mais la réalité fait apparaître un ensemble de dates portées relativement important.

14. À mettre sur le compte de la «modernité» de ces logis, cette curieuse mention que l'on rencontre systématiquement sur les descriptions notariées de ces logis au XVII ${ }^{\mathrm{e}}$, mais encore au XVIII ${ }^{e}$ siècle. Le notaire insiste sur le fait que la pièce est "doublée de plancher ", c'est-à-dire qu'un plancher sépare le rez-de-chaussée du comble. Sans doute tenait-il à insister sur le contraste entre ces logis neufs et l'archaïsme des anciennes « huttes » dont la pièce était encore sous charpente, phénomène qui s'observe encore dans le vignoble nantais et les marais du nord de la Vendée.

15. Bardisa, Marie. Pressigny en Touraine : architecture et peuplement de la basse vallée de la Claisse jusqu'au XVI ${ }^{\mathrm{e}}$ siècle. Orléans, 1997 (Cahiers du patrimoine, $\mathrm{n}^{\circ} 47$ ).

16. Le vocabulaire de l'architecture établit une nuance entre ces deux appellations, chantignolle et tasseau, sur la foi de profils de charpente publiés par Le Muet au XVII ${ }^{e}$ siècle. Nous considérerons que l'on a fait, dans le cas présent, l'économie de l'une de ces deux pièces, qui permet à la fois de solidariser arbalétrier et chevron et de porter la panne. 
17. Que les Bretons me pardonnent cette incursion sur leur territoire: il m'a été donné de repérer des charpentes similaires sur des logis du pays de Vannes.

18. Canton de La Ferté-Bernard. Inventaire topographique ${ }^{\circ}{ }^{14}$. Paris : Imp. Nationale, 1983. La terre provenant du creusement de la mare servait du mortier, d'où l'appellation de mortier souvent donnée à celle-ci.

19. Meirion-Jones, Gwyn. La maison longue en Bretagne (I) et (II). Archéologie en Bretagne, $n$ - 26 (1980) et $\mathrm{n}^{\circ} 27$ (1980).

20. Toutefois, Hubert Maheux signale un logis de ce type dans la commune de Sion-les-Mines, (Voir : Hubert Maheux : Champs ouverts, habitudes communautaires et villages en alignements dans le nord de la Loire-Atlantique: des micro-sociétés fossilisées dans l'Ouest bocager [document électronique]. Paris : Ministère de la Culture et de la Communication, revue In Situ, $\mathrm{n}$ $\circ 5$, décembre 2004). Le plan qu'il publie (fig. $n^{\circ} 17$ ) me ferait plutôt penser à celui d'un logis « double» (cf. infra).

21. Un vieux souvenir de lecture (où ? quand ? comment ?) me rappelle une disposition similaire en Bretagne, peut-être dans le Finistère. Si un chercheur de Bretagne pouvait me rafraîchir la mémoire, je lui en serais infiniment reconnaissant.

22. Voir notre article : Maison de terre et de roseau : regards sur la bourrine du marais de Monts [document électronique]. Paris : Ministère de la Culture et de la Communication, revue In Situ, n ${ }^{\circ}$ 7, février 2006.

23. Appellation confirmée par Joseph-Stany Gauthier. Les maisons rurales de la Loire-Atlantique. Congrès de l'Association bretonne et Union régionaliste bretonne (1950). Folklore de la LoireInférieure $1^{\text {ère }}$ partie l'habitat, 1956, p. 47 (Dans le pays de Châteaubriant, on appelle chambre l'appartement qu'on n'habite pas dans la ferme et qui sert de débarras). Cette information m'a été confirmée par des personnes âgées.

\section{RÉSUMÉS}

Mon propos part d'un constat, celui de la généralisation de l'usage de la maçonnerie dans la mise en œuvre de la maison paysanne, qui entraîne les questions suivantes : à quel type d'habitat "primitif» ces nouvelles constructions ont-elles succédé? Quels indices chronologiques permettent de situer dans le temps, variable suivant les régions considérées, cette substitution (archives; inscriptions; critères techniques: charpente, mise en œuvre de la maçonnerie; stylistiques: encadrement des baies, cheminées)? Cette approche particulière, dont les conclusions tendent à l'élaboration d'une chronologie de l'habitat paysan, implique la prise en compte des modalités de cette substitution. Son intérêt est d'autant plus grand que celle-ci invite à s'interroger sur les usages et donc sur le « programme » de la maison paysanne.

This article is based on the observation of how masonry came to be used in the construction of peasant dwellings. This observation in the field raises the following questions. What was the 'primitive' nature of these constructions? What are the chronological indicators, different from one region to another, that permit precise dating for this appearance of masonry: archival sources, inscriptions, technical criteria, structural forms, nature of the masonry, stylistic considerations, surrounds of windows and doors, chimneys? This approach to the question can lead to a certain degree of precision in the dating of peasant dwellings, and implies a new 
appraisal of the ways this substitution took place. It is all the more interesting in so far as it raises interrogations about the uses of the peasant house, its architectural 'brief'.

\section{INDEX}

Mots-clés : demeure rurale, maison paysanne, Sablé-sur-Sarthe, La Flèche, L'Anjou, Le Maine, Marais du nord de la Vendée, Presqu'île guérandaise, architecture rurale, critères de datation, Jean-Marie Pérouse de Montclos, André Mussat, hutte primitive, Joseph Rykwert, archéologie, bourrine, construction en bauge, loge couverte, resserres, Joseph-Stany Gauthier, maison latine, maison gauloise, cheminée, façade, charpente, mortier, logis mixte, logis double, maison longue

\section{AUTEUR}

\section{FRANÇOIS LE BCEUF}

Chercheur. Service régional de l'inventaire des Pays de la Loire 